\title{
A Review of Scales to Evaluate Sleep Disturbances in Movement Disorders
}

\author{
Mónica M. Kurtis ${ }^{1 *}$, Roberta Balestrino ${ }^{2}$, Carmen Rodriguez-Blazquez ${ }^{3}$, \\ Maria João Forjaz ${ }^{4}$ and Pablo Martinez-Martin ${ }^{3}$
}

\begin{abstract}
${ }^{1}$ Movement Disorders Unit, Neurology Department, Hospital Ruber Internacional, Madrid, Spain, ${ }^{2}$ Department of Neuroscience Rita Levi Montalcini, University of Turin, Turin, Italy, ${ }^{3}$ National Center of Epidemiology and Centro de Investigación Biomédica en Red sobre Enfermedades Neurodegenerativas (CIBERNED), Institute of Health Carlos III, Madrid, Spain, ${ }^{4}$ National School of Public Health and Red de Investigación en Servicios de Salud en Enfermedades Crónicas (REDISSEC), Institute of Health Carlos III, Madrid, Spain
\end{abstract}

\section{OPEN ACCESS}

Edited by:

K. Ray Chaudhuri,

King's College London,

United Kingdom

Reviewed by:

Pedro Ribeiro,

Universidade Federal do

Rio de Janeiro, Brazil

Rou-Shayn Chen,

Chang Gung Memorial

Hospital, Taiwan

*Correspondence:

Mónica M. Kurtis

mkurtis@ruberinternacional.es

Specialty section:

This article was submitted

to Movement Disorders,

a section of the

journal Frontiers in Neurology

Received: 13 February 2018

Accepted: 07 May 2018

Published: 29 May 2018

Citation:

Kurtis MM, Balestrino R, Rodriguez-

Blazquez C, Forjaz MJ and

Martinez-Martin P (2018)

A Review of Scales to Evaluate

Sleep Disturbances in

Movement Disorders.

Front. Neurol. 9:369.

doi: 10.3389/fneur.2018.00369
Patients with movement disorders have a high prevalence of sleep disturbances that can be classified as (1) nocturnal sleep symptoms, such as insomnia, nocturia, restless legs syndrome (RLS), periodic limb movements (PLM), obstructive sleep apnea (OSA), and REM sleep behavior disorder; and (2) diurnal problems that include excessive daytime sleepiness (EDS) and sleep attacks. The objective of this review is to provide a practical overview of the most relevant scales that assess these disturbances to guide the choice of the most useful instrument/s depending on the line of research or clinical focus. For each scale, the reader will find a brief description of practicalities and psychometric properties, use in movement disorder cohorts and analyzed strengths and limitations. To assess insomnia, the Pittsburgh Sleep Quality Index, a generic scale, and three disease-specific scales: the Parkinson Disease Sleep Scale (PDSS), the PDSS-2, and Scales for outcomes in Parkinson's disease (PD)-Sleep-Nocturnal Sleep subscale are discussed. To evaluate nocturia, there are no specific tools, but some extensively validated generic urinary symptom scales (the Overall Bladder Questionnaire and the Overactive Bladder Symptom Score) and some PD-specific scales that include a nocturia item are available. To measure RLS severity, there are currently four domain-specific generic scales: The International Restless Legs Scale, the Johns Hopkins Restless Legs Severity Scale, the Restless Legs Syndrome-6 measure, a Pediatric RLS Severity Scale, and the Augmentation Severity Rating Scale (a scale to evaluate augmentation under treatment) and several instruments that assess impact on quality of sleep and health-related quality of life. To evaluate the presence of PLM, no clinical scales have been developed to date. As far as OSA, commonly used instruments such as the Sleep Apnea Scale of the Sleep Disorders Questionnaire, the STOP-Bang questionnaire, and the Berlin Questionnaire are reviewed. Three scales have been extensively used to assess EDS: the generic Epworth Sleepiness Scale, the Stanford Sleepiness Scale, and the PD-specific Scales for outcomes in PD-Sleep-Daytime sleepiness subscale. To date, only the Inappropriate Sleep Composite Score specifically evaluates propensity to sleep attacks.

Keywords: Parkinson's disease, Parkinsonism, chorea, dystonia, insomnia, nocturia, restless legs, sleep apnea 


\section{INTRODUCTION}

Sleep problems such as insomnia, nocturia, restless legs syndrome (RLS), periodic limb movements (PLMs), REM sleep behavior disorder (RBD), obstructive sleep apnea (OSA), and excessive daytime sleepiness (EDS) are prevalent in the general population and in movement disorder patients. Insomnia, for example, is a salient problem in Parkinson's disease (PD) (1), multiple system atrophy, progressive supranuclear palsy, and corticobasal degeneration (2), but also in patients with hyperkinetic disorders such as Huntington's chorea, neuroacantocytosis, and Tourette syndrome (3). Daytime sleepiness (DS) is one of the main features of Lewy body dementia and is also problematic in PD (4) and may be particularly influenced by treatment with dopamine agonists as well as levodopa.

Sleep disturbances affect quality of rest and health-related quality of life (HRQoL) and may lead to problems during the waking hours, such as EDS, fatigue, and memory and attention difficulties. Nocturnal disturbances alter blood pressure, oxygen, and carbon dioxide blood levels and are thus well-established risk factors for cardio-cerebrovascular diseases. On the other hand, DS and sleep attacks impair social and working function and are highly dangerous if subjects are driving a vehicle, with evident implications beyond the patient.

Therefore, diagnosis and treatment of sleep disorders is a priority for clinicians but also for health policy makers. Diagnosis of insomnia is based on the subject's perception of sleep quality while diagnosis of nocturia, and RLS is based on careful clinical history and evaluation. Many instruments have been designed to detect these problems, measure their severity, evaluate their effect on quality of life, and assess their change in time or after intervention. The diagnostic criteria of other sleep disturbances, such as PLMs, RBD, and OSA, are defined by polysomnographic (PSG) data. For EDS and sleep attacks, objective tests such as the Sleep Latency Test (MSLT) and the Maintenance of Wakefulness Test (MWT) are used. PSG is not a useful ancillary test to diagnose EDS, although it can be useful to identify underlying sleep disorders (5). However, these laboratory tests are highly demanding in terms of cost, human resources, and other logistics required; therefore, questionnaires and scales have been developed for screening patients and thus make recommendations for further testing.

Questionnaires are patient-based instruments that allow for the evaluation of signs and symptoms that cannot be observed in the clinic (i.e., insomnia or nocturia) and may include subjective features based on the patient's perception and judgment of the symptom and its impact on his/her life. As such, they are considered patient-related outcomes and have the advantage of shifting the focus to the patient, a requirement in the current biopsychosocial model of patient-centered medicine.

The objective of this review is to provide the clinician and researcher with an overview of the scales that are currently available to screen and measure the severity of these sleep disturbances (except RBD, which is the focus of another article in this issue). All the reviewed scales are questionnaires and are organized by type (generic, disease-specific, and HRQoL) and chronologically by year of publication. After a practical description of each scale including diagnostic accuracy (for screening instruments, where available), the psychometric properties and application in different movement disorder cohorts are discussed, along with the instruments' advantages and disadvantages.

\section{METHODS}

The literature search was based on the pubmed database and included articles published before January 31, 2018 and written in English, Italian, French or Spanish. The combined MeSH search terms used were: ("insomnia" OR "nocturia" OR "restless legs" OR "periodic leg movements" OR "obstructive sleep apnea" OR "excessive daytime sleepiness" OR "sleep attacks" OR "sleep disturbance") AND ("Parkinson's disease"). A similar search strategy was performed with the following terms: "multiple system atrophy," "dementia with lewy bodies," "progressive supranuclear palsy," "corticobasal degeneration," "dystonia," "chorea," "Huntington's chorea," "tics," "Tourette." The identified articles were perused for the use of scales or questionnaires for screening or diagnosis of the sleep disturbances under review, and their references were also searched for other sleep disturbance scales. For each identified measuring instrument, psychometric properties were noted from the original developers of the instrument and completed with further clinimetric investigations when available. With all identified generic scales, a similar search strategy was used to identify their use in the different movement disorder populations mentioned above. The extracted information was initially discussed and agreed by two authors (Mónica M. Kurtis and Roberta Balestrino), and their consensus was reviewed by the other authors to obtain a final agreement of the most relevant scales.

\section{NOCTURNAL SLEEP (NS) DISTURBANCES}

\section{Insomnia}

The diagnostic criteria of "insomnia syndrome" include the following: (1) difficulty falling asleep, awakenings during the night or waking up too early, (2) despite adequate sleep circumstances, and (3) symptoms during wakefulness, such as attention problems or fatigue, due to the lack of sleep (6). Thus, the diagnosis depends on self-reported outcomes, not on a specific amount of sleep or other objective sleep measures. Insomnia can be classified as primary or secondary; however, it is often hard to establish the cause, effect, or coexistence of conditions that are associated with insomnia such as psychiatric disorders. Thus, the term "comorbid" is preferable to "secondary." Insomnia is a frequent complaint in movement disorder patients and has been extensively studied in PD, chorea, and antibody-mediated encephalopathies manifesting with movement disorders.

\section{Pittsburgh Sleep Quality Index (PSQI) \\ Scale Description}

The PSQI is a generic, 19 items self-rated scale designed to measure overall sleep problems (7). A score above 5 distinguishes between "good" and "poor" sleepers with a high sensitivity and specificity $(7,8)$ (Table $\mathbf{1})$. 
TABLE 1 | Scales that evaluate insomnia in movement disorders.

\begin{tabular}{|c|c|c|c|c|c|c|}
\hline Scale & Overview & Scoring & $\begin{array}{l}\text { Cut off } \\
\text { Diagnostic accuracy }\end{array}$ & $\begin{array}{l}\text { Time } \\
\text { frame }\end{array}$ & Administration & Languages \\
\hline PSQI (7) & $\begin{array}{l}\text { Generic } \\
\text { Assesses overall } \\
\text { sleep quality }\end{array}$ & $\begin{array}{l}19 \text { items are combined to form seven component } \\
\text { scores (subjective sleep quality, sleep latency, sleep } \\
\text { duration, habitual sleep efficiency, sleep disturbances, } \\
\text { use of sleeping medication, and daytime dysfunction). } \\
\text { Items are scored from } 0 \text { to } 3 \text { (no difficulty to severe } \\
\text { difficulty). Total scores range from } 0 \text { to } 21 \text {, where } \\
\text { higher scores indicating more severe difficulties in } \\
\text { the different areas }\end{array}$ & $\begin{array}{l}>5 \text { "bad sleepers" } \\
\text { Sensitivity } 90-98 \% \\
\text { Specificity } 84-86 \% \\
(7,8)\end{array}$ & $\begin{array}{l}\text { Previous } \\
\text { month }\end{array}$ & $\begin{array}{l}\text { Self-rated } \\
10 \mathrm{~min}\end{array}$ & $\begin{array}{l}\text { Public domain } \\
\text { English } \\
\text { Spanish }\end{array}$ \\
\hline PDSS (17) & $\begin{array}{l}\text { PD specific } \\
\text { Measures nocturnal } \\
\text { problems and } \\
\text { daytime sleepiness }\end{array}$ & $\begin{array}{l}15 \text { items rated on visual analog scale }(0-10) \text {. Range } \\
0-150, \text { where higher scores indicate more severe } \\
\text { sleep problems. Weighted toward severity }\end{array}$ & $\begin{array}{l}>82 \\
\text { AUC: } 0.85(95 \% \mathrm{Cl} \\
0.78-0.91) \\
\text { Sensitivity } 75 \% \\
\text { Specificity } 80 \% \\
(18)\end{array}$ & $\begin{array}{l}\text { Previous } \\
\text { week }\end{array}$ & $\begin{array}{l}\text { Self-rated } \\
10 \mathrm{~min}\end{array}$ & $\begin{array}{l}\text { Public domain } \\
\text { English } \\
\text { Japanese } \\
\text { Spanish } \\
\text { Portuguese }\end{array}$ \\
\hline PDSS-2 (21) & $\begin{array}{l}\text { PD specific } \\
\text { NS problems }\end{array}$ & $\begin{array}{l}15 \text { items scored from } 0 \text { (never) to } 4 \text { (very frequent). } \\
\text { Range 0-60, where higher scores indicate more } \\
\text { sleep problems }\end{array}$ & $\begin{array}{l}\geq 15 \\
\text { Sensitivity } 72.1 \% \\
\text { Specificity } 72.9 \% \\
(21)\end{array}$ & $\begin{array}{l}\text { Previous } \\
\text { week }\end{array}$ & $\begin{array}{l}\text { Self-rated } \\
10 \mathrm{~min}\end{array}$ & $\begin{array}{l}\text { Public domain } \\
\text { English } \\
\text { Spanish }\end{array}$ \\
\hline $\begin{array}{l}\text { SCOPA-Sleep- } \\
\text { NS (11) }\end{array}$ & $\begin{array}{l}\text { PD specific } \\
\text { Measures NS } \\
\text { problems and } \\
\text { sleep quality }\end{array}$ & $\begin{array}{l}\text { The NS subscale has } 5 \text { items scored from } 0 \text { (not at all) } \\
\text { to } 3 \text { (very much). Range 0-15. Higher scores indicate } \\
\text { more severity. One item on sleep quality is rated on } \\
\text { 7-point scale, } 0 \text { (very well) to } 7 \text { (badly) }\end{array}$ & $\begin{array}{l}>7 \\
\text { AUC } 0.96 \\
\text { (Cl 0.93-0.98) } \\
\text { Sensitivity 97\% } \\
\text { Specificity } 80-88 \% \\
(11,18)\end{array}$ & $\begin{array}{l}\text { Previous } \\
\text { month }\end{array}$ & $\begin{array}{l}\text { Self-rated } \\
5 \text { min }\end{array}$ & $\begin{array}{l}\text { Public domain } \\
\text { Dutch } \\
\text { English } \\
\text { Spanish } \\
\text { Thai }\end{array}$ \\
\hline
\end{tabular}

AUC, area under the curve; CI confidence interval; NS, nocturnal sleep; PDSS, Parkinson Disease Sleep Scale; PSQI, Pittsburg Sleep Quality Index; SCOPA, Scales for outcomes in $P D$; $P D$, Parkinson's disease.

\section{Psychometric Properties}

The scale has shown high internal consistency and homogeneity (Cronbach's alpha $=0.80-0.83)(7,9)$. A factor scoring model based on three different domains (sleep efficiency, perceived sleep quality, and daily disturbances) is suggested (10). This scale shows strong correlation with SCOPA-Sleep but not with PSG, except for sleep latency $(7,11)$.

\section{Use in Different Movement Disorder Populations}

The scale has been extensively used in primary insomnia, dementia, depression and anxiety but also in movement disorders such as PD (12), MSA, PSP (13), and Huntington's disease (14). It has shown sensitivity to change in PD cohorts after interventions such as deep brain stimulation (15) and pharmacological treatment (16).

\section{Strengths and Limitations}

The PSQI is a generic scale with strong psychometric attributes that has been used in different movement disorders populations and reliably measures overall sleep problems. The scale was "recommended" by the MDS Task Force that reviewed clinical scales assessing sleep in PD as a screening tool and a measure of severity for overall sleep problems (10). The PSQI has the limitations of a self-rated scale (unreliable in dementia populations), although it does include 5 items to be filled out by the caregiver that are not included in the total score. It is heavily weighted toward sleep habits and does not adequately cover other sleep disturbances such as motor problems at bedtime (akinesia, dystonia, or chorea), RLS, REM Sleep Behavior Disorder (RBD) or DS. Furthermore, questions addressing respiratory disturbances and awakening may be confounders since they may be secondary to different problems, and scoring is complex.

\section{Parkinson Disease Sleep Scale (PDSS) Scale Description}

The PDSS (17) is a PD-specific, 15 item self-rated scale that preferentially evaluates NS problems, with only one item pertaining to DS [see Nocturnal Sleep (NS) Disturbances]. Each item is rated on a $0-10$ visual analog scale (VAS), total score ranging from 0 to 150. A cutoff score above 82 indicates the presence of NS problems with acceptable sensitivity and specificity (18) (Table 1).

\section{Use in Different Movement Disorder Populations}

The PDSS has been extensively used in PD and there is some experience in a dystonia cohort including patients with generalized, segmental, and focal dystonia (19).

\section{Psychometric Properties}

The PDSS has been validated in PD patients in all stages (20). Internal consistency and test-retest reliability are high [Cronbach's alpha $=0.77$ and intraclass correlation coefficient $($ ICC) $=0.94$, respectively] (17). Floor and ceiling effects are low, and there is significant correlation between 11 of the 15 items (20). The PDSS has shown strong correlation with the SCOPA-Sleep-NS (18).

\section{Data From Different Populations}

The PDSS has been widely used in different PD populations and distinguishes between $\mathrm{PD}$ patients and controls and drug naïve, mild and long-standing PD patients. 


\section{Strengths and Limitations}

The PDSS has demonstrated good psychometric characteristics. The scale is "recommended" by the MDS Task Force as a screening tool and severity measure for sleep symptoms in PD as it includes most of the patient's possible disturbances (10). However, patients require explanation on how to score the VAS, and the scale does not include information from the caregiver. It does not address respiratory difficulties such as sleep apnea and specific sleep disturbances such as RBD and RLS are partially addressed but wording is ambiguous. Finally, the scale only has one item regarding DS and thus is not recommended to assess diurnal sleep problems in PD.

\section{Parkinson Disease Sleep Scale-2 Scale Description}

The PDSS-2 (21) is the second version of the PDSS and has two main differences with the first version of the PDSS (see above): items are scored on a Likert scale (from $0=$ never to $4=$ very frequent), and all 15 items evaluate NS problems. Total scores range from 0 to 60 , and higher scores indicate higher severity. A cut of score above or equal to 15 distinguishes "bad" sleepers from good sleepers with acceptable diagnostic accuracy (21) (Table 1).

\section{Psychometric Properties}

The scale has shown acceptable inter-item correlations $(>0.30)$ and internal consistency (Cronbach's alpha, 0.73). Test-retest reliability is also satisfactory (ICC $=0.80$ ). Factor analysis resulted in a strong main factor that justifies summing all the items into a total scale, but also a three factors solution explaining $42.75 \%$ of variance, which suggested a hierarchical scale structure. The three subscales are night-time motor problems, $\mathrm{PD}$-specific symptoms, and sleep-specific symptoms (21).

\section{Strengths and Limitations}

Like the previous version, the PDSS-2 has shown good psychometric characteristics and has been extensively used in PD and is thus recommendable for screening and measuring severity of sleep disturbances in PD. This Likert scaling is easier for patients to understand, although scoring in item 1 is inverted which may be confusing.

\section{SCOPA-Sleep (NS Subscale)}

\section{Scale Description}

The Scales for Outcomes in PD-Sleep (SCOPA-Sleep) (11) is a $\mathrm{PD}$-specific scale that includes 12 items to measure sleep quality, NS disturbances, and DS. The NS subscale includes 5 items on insomnia, multiple awakenings, sleep efficiency, and duration plus one single item on overall sleep quality. A cutoff score of 7 has demonstrated excellent sensitivity and satisfactory specificity $(11,18)$ (Table 1).

\section{Psychometric Properties}

The internal consistency of the NS subscale is high (Cronbach's alpha $=0.88-0.84)$, and test-retest reliability is excellent $($ ICC $=0.94)(11)$. Factor analysis revealed one factor accounting for $68.1 \%$ of the variance, thus demonstrating that this subscale measures a single construct (11). The SCOPA-Sleep-NS has shown strong correlations with other instruments such as the PSQI $(r=0.83)(11)$ and the PDSS $(r=0.60)(18)$.

\section{Strengths and Limitations}

The NS subscale of the SCOPA-Sleep has shown strong psychometric properties and has been extensively used, discriminating between subjects and controls and PD patients in different stages. The subscale is a "recommended" tool for screening and for measuring severity of overall sleep problems in PD (10). However, sensitivity to change has not been investigated and, similarly to the PDSS, the scale lacks specific items addressing RLS and RBD.

\section{Multidomain Scales}

Some multidomain PD-specific scales, such as the Non-Motor Symptom Questionnaire (NMSQuest) (22), the Non-Motor Symptom Scale (NMSS) (23), and the Movement Disorder Society Unified Parkinson Disease Rating Scale (MDS UPDRS) part 1B (24) include a single item that evaluates insomnia. The NMSS is a rater-based scale that evaluates both severity and frequency of thirty different non-motor symptoms seen in PD, considering the past month. Item 5 has been used to evaluate difficulty falling asleep or staying asleep in other hypokinetic disorders such as MSA and PSP (25). The NMSQuest and the MDS UPDRS part 1B are both self-rated questionnaires. Question 23 on the NMSQuest evaluates difficulty falling asleep or maintaining sleep while item 1.7 of the MDS UPDRS asks the patient to give an overall score on sleep quality in the past 7 days. Another disease-specific scale for another parkinsonism, the Progressive Supranuclear Palsy Rating Scale (26) includes one item on sleep difficulty, rated from 0 to 4 , in the activities of daily living part. These scales have demonstrated excellent psychometric characteristics, although the validity and reliability of single items has not been tested yet.

\section{Conclusion}

Only the PSQI can be recommended for screening and assessing severity of insomnia in any type of movement disorders since it is a generic scale with satisfactory psychometric properties and extensive use. There are three PD-specific scales that can be recommended in patients with this disease. There are single items on PD-specific multidomain scales that assess insomnia, but these single items have insufficient psychometric data on validity and reliability.

\section{Nocturia}

Nocturia is defined as "waking up to pass urine during the main sleep period," and it is a common phenomenon although patients tend to under-report this symptom (27). Nocturia can be due to different causes, such as renal, urological, vascular, or neurological diseases and medications, and etiology ranges widely by gender and age group. Similarly to other sleep disturbances, consequences of nocturia include lower sleep quality with eventual daytime consequences. Furthermore, nocturia is associated with falls and bone fractures, therefore increasing morbidity and, in elderly populations, mortality (27). Nocturia is highly frequent in patients with $\mathrm{PD}$ and can exacerbate sleep fragmentation among this population (28). 


\section{Overactive Bladder Questionnaire (OAB-q) Scale Description}

The OAB-q (29) is a generic, self-rated, 33 items scale developed to measure symptoms of overactive bladder (OAB), which include urinary frequency, nocturia, and urgency, with or without incontinence. The scale is made up of two subscales: a symptom bother scale ( 8 items), rated 1 (not at all) to 6 (a very great deal) and an HRQoL scale (HRQoL) (25 items), rated 1 (none of the time) to 6 (all the time). Two items of the symptom bother scale assess nocturia, and five of the HRQoL scale are related to sleep. The time frame is the past 4 weeks. It takes about $20-25 \mathrm{~min}$ to complete. A shorter form, the OAB-q SF, made up of 19 items (6 symptom bother items and 13 HRQoL items) was developed by the original authors and includes nocturia ( 1 item) and impact on sleep quality (2 items) (30).

\section{Psychometric Properties}

Factor analysis provided a four factors solution for the HRQoL items (one of them being sleep) (29). Internal consistency is high with subscale Cronbach's alpha-values ranging from 0.86 to 0.94 (29). The questionnaire has also demonstrated adequate test-retest reliability (31) and satisfactory responsiveness (32). The shorter form has also shown appropriate convergent validity, discriminant validity, internal reliability, reproducibility, and responsiveness to change (30).

\section{Scale Use in Movement Disorders}

In $\mathrm{PD}$, the OAB-q has been used to evaluate the correlation of bladder dysfunction and motor impairment (33), while its short form has been used to evaluate the effect of percutaneous posterior nerve stimulation on detrusor (34) but no published experience in other movement disorder cohorts was found.

\section{Strengths and Limitations}

The OAB-q has been extensively used due to its robust psychometric characteristics and because it assesses severity of symptoms and impact on quality of life. It can be found in several languages and a short form is available. However, studies demonstrating sensitivity to change of the OAB-q are lacking. The psychometric properties of the items on nocturia have not been investigated nor their impact on sleep quality. Finally, data in movement disorders patients are only available for PD patients.

\section{Overactive Bladder Symptom Score (OABSS) Scale Description}

The OABSS (35) is another generic, self-rated scale with 4 items that include: daytime urinary frequency (scored $0-2$ ), nocturia (from 0 , never wake up to urinate, to 3 , wake up $\geq 3$ times to urinate), urgency $(0-5)$, and incontinence $(0-5)$. Thus, the total score ranges from 0 to 15 , where higher scores indicate more severity. The time frame is the past week, and the questionnaire takes about 3-4 min to complete.

\section{Psychometric Properties}

In patients with $\mathrm{OAB}$, each symptom score correlated positively with the total OABSS $\left(r_{\mathrm{S}}=0.10-0.78\right)$, and the scale showed good internal consistency (Cronbach's alpha $=0.74$ ) and high testretest reliability (weighted kappa coefficients were $0.80-1.0$ for each symptom score and 0.86 for OABSS). The OABSS showed moderated correlations with quality of life scores assessed by the King's Health Questionnaire $(r=0.20-0.49)$. The OABSS discriminated patients with $\mathrm{OAB}$ from controls and showed sensitivity to change after therapeutic intervention (35).

\section{Use in Movement Disorders}

The OABSS has been recently used in two PD cohorts to evaluate urinary symptoms, including nocturia. Mito et al investigated PD patients without treatment and found moderate correlations between OABSS and the UPDRS motor scores $\left(r_{S}=0.39\right)$, particularly with the akinetic-rigid subscore $\left(r_{\mathrm{S}}=0.47\right)(36)$. Another study investigated the correlation between urinary disturbances and falls in 90 patients with PD and did not find a relationship between nocturia and falling (37). To the best of our knowledge, the scale has not been used in other movement disorders.

\section{Strengths and Limitations}

The OABSS is a fast and easy to use scale that has demonstrated content and construct validity and internal consistency in measuring urinary disturbances in $\mathrm{OAB}$ syndrome. However, the psychometric properties of the single item on nocturia have not been sufficiently investigated, and data for movement disorders populations are limited to $\mathrm{PD}$.

\section{Urinary Symptom Profile (USP) Scale Description}

The USP is a 13 item, self-rated scale that evaluates three dimensions of urinary disturbances: stress urinary incontinence, $\mathrm{OAB}$, and low stream symptoms (38). The $\mathrm{OAB}$ domain includes two items on nocturnal urinary symptoms. The time frame includes symptoms in the past 4 weeks.

\section{Psychometric Properties}

The scale has demonstrated robust psychometric qualities with good internal consistency, convergent validity, and test-retest reproducibility. In the validation study, USP dimension scores were good predictors of urinary disorder presence and identification and correlated with micturition diaries (38).

\section{Use in Movement Disorders}

To the best of our knowledge, the scale has only been used in a population of functional movement disorders patients who reported lower urinary tract symptoms (39).

\section{Strengths and Limitations}

Although this is the first scale to comprehensively assess the main dimensions of urinary disturbances in both sexes and the psychometric properties are more than adequate, the UPS has scarcely been studied in movement disorders patients. The nocturia items have not been investigated separately to evaluate their psychometric properties.

\section{Other Generic Urinary Symptom Scales}

There are four generic questionnaires designed to assess lower urinary tract symptoms associated with benign prostatic enlargement in men that have excellent psychometric properties (validity and reliability) and include an item on nocturia. 
Of these, the most extensively used, probably due to simplicity and fast completion, is the American Urological Association symptom score (40), also known as the International Prostate Symptom Score. The Danish Prostate Symptom Score (41) and the International Continence Society (ICS) ICSmale questionnaire (42) are very complete but requires more time and harder to score. The shortened version of the latter, the ICSmale Short Form (43), provides a good alternative and has been used in a Huntington's disease population (44).

\section{PD-Specific Multidomain Scales}

The NMSQuest (22), the NMSS (23), and the SCOPA-Autonomic (45) include an item on nocturia. Item 24 on the NMSS and item 9 on the NMSQuest evaluate whether the patient has to get up during the night to urinate. The SCOPA-Autonomic is a tool that evaluates the range of dysautonomic symptoms that most affect PD patients and item 13 evaluates the frequency of nocturia. These single items have not been properly investigated to establish their psychometric properties and reliability to screen for and measure severity of nocturia in PD.

\section{Conclusion}

There is no scale designed solely for the evaluation of nocturia and its effect on sleep. The available measurements include generic scales that measure lower urinary tract dysfunction, including nocturia, and $\mathrm{PD}$-specific scales that address a range of non-motor symptoms that are prevalent in this movement disorder, including nocturia.

\section{Restless Legs Syndrome}

Restless legs syndrome is a neurological disorder characterized by the presence of unpleasant sensations that patients describe as creeping, crawling, itching, tingling, pulling, or painful sensations, more commonly, but not exclusively, in the lower limbs. Moving the interested limb or standing up, walking or stretching can release these sensations, thus the name of the disease. RLS is relatively common, with prevalence rates ranging from 3.9 to $15 \%$ in the general population; is more common among Caucasians and older people, although it can affect children as well (46). Approximately $10 \%$ of patients seek medical help, and the most common complaints are difficulty in sleeping/daytime activities and an overall lower HRQoL (47). The diagnostic criteria have been recently revised by the International Restless Legs Syndrome Study Group (48).

There are three scales to assess the severity of RLS, one scale to assess the augmentation phenomenon, three scales that assess HRQoL and two scales that assess the impact of RLS on sleeping and on daily functioning, although just one has been validated (Table 2). One pediatric scale has been designed but has not been validated. Two PD multidomain scales have an item to assess symptoms that are compatible with RLS.

\section{Johns Hopkins Restless Legs Severity Scale (JHRLSS)}

Scale Description

The JHRLSS is a short scale used to assess the usual time of onset and severity of symptoms of RLS and consists one sole item (49) (Table 2).

\section{Psychometric Properties}

This scale showed a strong correlation with sleep efficiency, as assessed by an all-night polysomnogram $\left(r_{\mathrm{S}}=0.60\right)$ and moderate correlation with Periodic Limb Movements (PLMs) per hour of sleep $\left(r_{\mathrm{S}}=0.45\right)$. The JHRLSS inter-rater reliability was excellent: Spearman's rank coefficient was 0.91 , and Cramer's $V$ for interrater agreement was $0.87(49)$.

\section{Data From Different Populations}

It has been validated in an adult population of RLS patients, with symptoms at least 5 days/week (50). We did not find any data regarding its use on other populations.

\section{Strengths and Limitations}

The JHRLSS is an easy and fast instrument to administer to obtain additional information on RLS. It showed correlation with objective measures of the disease. In a revision of instruments to assess the severity of RLS performed by the MDS Task Force (50), this scale was rated as "suggested" for RLS patients with frequent symptoms (5 days a week or more) since no data on its responsiveness were available. There are no published data on populations other than adults with RLS. Importantly, the demarcation point for "evening" (6:00 p.m.) might need to be adjusted based on geographic and cultural characteristics of the population. It does not provide information on other important aspects of the disease such as severity, impact on sleep, or HRQoL.

\section{International Restless Legs Scale (IRLS) Scale Description}

The IRLS (51) is a 10-item questionnaire with two subscales, one assessing symptoms and one evaluating how bothersome they are to the patient. It is probably the most widely used tool to evaluate severity and impact on quality of life of RLS (Table 2).

\section{Psychometric Properties}

Factor analysis showed two factors, "Severity of symptoms" and "Life Impact," with a total of $64.3 \%$ of the variance explained. Internal consistency was satisfactory (Cronbach's alpha $=0.93-0.95$ ) and corrected item-total correlations acceptable $(>0.40)$. Reliability was adequate: after 2 weeks, the ICC was 0.87 , and interrater reliability was $0.93-0.97$. It showed strong correlation with other scales such as the Clinician's Global Impression of Severity (CGIS) (0.73-0.74) and the Patient Global Impression (0.78-0.82). The IRLS differentiates a group of RLS patients from a normal control group and a sleep-disorder control group (51). The scale has demonstrated responsiveness (52).

\section{Data From Different Populations}

The scale was originally validated in an adult population of RLS patients. It has been used to study prevalence of RLS in PD and controls (53) and to compare the prevalence or RLS in different movement disorders: PD, PSP, and MSA (13). The scale has also been recently used in Huntington's disease (54).

\section{Strengths and Limitations}

This scale was rated as "recommended" by the MDS Task Force (50). It is the primary instrument used to determine RLS severity, 
TABLE 2 | Scales that evaluate restless legs syndrome.

\begin{tabular}{|c|c|c|c|c|c|c|}
\hline Scale & Overview & Scoring & $\begin{array}{l}\text { Cut off } \\
\text { Diagnostic accuracy }\end{array}$ & Time frame & Administration & Languages \\
\hline JHRLSS (49) & $\begin{array}{l}\text { RLS specific } \\
\text { Assesses the usual time of } \\
\text { onset/severity of symptoms }\end{array}$ & $\begin{array}{l}1 \text { question on what time of day the RLS appears, with answers } \\
\text { ranging from } 0 \text { (no symptoms) to } 3 \text { (day and night symptoms) }\end{array}$ & No established cutoff & $\begin{array}{l}\text { Lifetime } \\
\text { (50\% of days) }\end{array}$ & $\begin{array}{l}\text { Clinician rated } \\
1 \text { min }\end{array}$ & English \\
\hline IRLS (51) & $\begin{array}{l}\text { RLS specific } \\
\text { Most used scale to assess } \\
\text { severity of RLS }\end{array}$ & $\begin{array}{l}10 \text { items in total. Answers range from "no RLS or impact (0)" } \\
\text { to "very severe RLS or impact (4)" } \\
2 \text { subscales: symptoms and symptoms impact } \\
\text { Total score that ranges from } 0 \text { to } 40\end{array}$ & No established cutoff & Previous week & $\begin{array}{l}\text { Clinician rated } \\
10 \text { min }\end{array}$ & $\begin{array}{l}\text { English, Japanese, Hindi, } \\
\text { Brazilian Portuguese, and } \\
\text { translations performed by } \\
\text { MAPI Research Trust }{ }^{\mathrm{a}}\end{array}$ \\
\hline RLS-6 $(55,56)$ & $\begin{array}{l}\text { RLS specific } \\
\text { Assess severity of RLS } \\
\text { at different times of a } 24 \mathrm{~h} \\
\text { period }\end{array}$ & $\begin{array}{l}6 \text { items, scored on a } 0-10 \text { scale }(0=\text { no symptom, } 10=\text { very } \\
\text { severe). No total score, separate scores for } 4 \text { domains: sleep } \\
\text { quality (items } 1+6) \text {; RLS at night time (items } 2+3) \text {; daytime } \\
\text { manifestations during relaxation (item 4); and during activity } \\
\text { ("RLS mimics") (item 5) }\end{array}$ & No established cutoff & Previous week & $\begin{array}{l}\text { Clinician rated } \\
10 \text { min }\end{array}$ & English \\
\hline ASRS (57) & $\begin{array}{l}\text { RLS specific } \\
\text { Measures RLS before and } \\
\text { after dopaminergic treatment }\end{array}$ & $\begin{array}{l}3 \text { items cover where symptoms begin and the onset. Each item } \\
\text { is scored "0" (improvement after treatment), worsening score } \\
\text { ranges between } 1 \text { ("mild") and } 8 \text { ("severe"). Total score ranges } \\
\text { from } 0 \text { to } 24 \text { following an algorithm }\end{array}$ & $\begin{array}{l}\geq 5 \\
\text { Sensitivity } 82 \% \\
\text { Specificity } 92 \% \\
(57)\end{array}$ & Previous week & $\begin{array}{l}\text { Clinician rated } \\
10 \text { min for the } \\
\text { scale and } 5 \text { min to } \\
\text { calculate the score }\end{array}$ & $\begin{array}{l}\text { English and translations } \\
\text { performed by MAPI } \\
\text { Research Trust }{ }^{\mathrm{b}}\end{array}$ \\
\hline RLS-QLI (58) & $\begin{array}{l}\text { RLS specific } \\
\text { Measures impact } \\
\text { of RLS on HRQoL }\end{array}$ & $\begin{array}{l}17 \text { items in } 4 \text { domains: daily function, social function, sleep } \\
\text { quality, and emotional well-being. Scores for each domain can } \\
\text { be calculated as explained in the scale. Total scores range } \\
\text { between } 0 \text { and } 100 \text { (lower scores mean lower HRQoL) }\end{array}$ & No established cutoff & Previous month & $\begin{array}{l}\text { Self-rated } \\
15 \text { min for the } \\
\text { scale and } 5 \text { min } \\
\text { for the score }\end{array}$ & English \\
\hline ARLSQoL (60) & $\begin{array}{l}\text { RLS specific } \\
\text { Measures impact of RLS } \\
\text { on daily life, emotional well- } \\
\text { being, social life and work }\end{array}$ & $\begin{array}{l}18 \text { items. } 10 \text { items are scored on a 5-point scale, and form a } \\
\text { single summary score, the overall life impact score (lower scores } \\
\text { indicate worse HRQoL). The remaining } 8 \text { items are recorded as } \\
\text { either a numerical value or a dichotomous response and concern } \\
\text { daily activities (one question), sexual interest (two questions) and } \\
\text { work (five questions) }\end{array}$ & No established cutoff & Previous 4 weeks & $\begin{array}{l}\text { Self-rated } \\
10 \text { min }\end{array}$ & $\begin{array}{l}\text { Dutch, Finnish, French, } \\
\text { German, Greek, } \\
\text { Hungarian, Italian, } \\
\text { Hindi, and Japanese }\end{array}$ \\
\hline KRLS-QoL (62) & $\begin{array}{l}\text { RLS specific } \\
\text { Measures impact } \\
\text { of RLS on HRQL }\end{array}$ & $\begin{array}{l}12 \text { items, } 5 \text { domains (effects of RLS symptoms; disturbed } \\
\text { sleep and its effects; effects of other features; handling the RLS } \\
\text { symptoms; overall impact on QoL). First } 11 \text { items are scored } \\
\text { from } 0 \text { (no impairment at all) to } 5 \text { (extreme impairment). Item } \\
12 \text { summarizes the impact on quality of life }\end{array}$ & No established cutoff & Previous 4 weeks & $\begin{array}{l}\text { Self-rated } \\
10 \mathrm{~min}\end{array}$ & English \\
\hline PSQ-RLS (63) & $\begin{array}{l}\text { RLS specific } \\
\text { Assesses impact of RLS } \\
\text { on sleeping and on daily } \\
\text { functioning }\end{array}$ & $\begin{array}{l}5 \text { single item domains (overall quality of sleep, ability to } \\
\text { function during the day, frequency of RLS symptoms, awakening } \\
\text { at night due to RLS, length of awakening in the night due to RLS } \\
\text { symptoms). } 4 \text { Items are assessed with a Likert scale (1-4 or } 1-5 \text { ); } \\
\text { one Item is an open-ended question on the number of nights per } \\
\text { week with RLS symptoms }\end{array}$ & No established cutoff & Previous week & $\begin{array}{l}\text { Self-rated } \\
5 \text { min }\end{array}$ & English \\
\hline
\end{tabular}

IRLS, International Restless Legs Scale; JHRLSS, Johns Hopkins Restless Legs Severity Scale; ASRS, Augmentation Severity Rating Scale; ARLSQoL, Restless Legs Syndrome Quality of Life Questionnaire/Abetz; RLS-QLI, Restless Legs Syndrome Quality of Life Instrument; KRLS-QoL, Kohnen Restless Legs Syndrome Quality of Life Questionnaire; PSQ-RLS, Post-Sleep Questionnaire for RLS; RLS-6, Restless Legs Syndrome-6; HRQoL, health related quality of life; RLS, restless legs syndrome.

aTranslations: Afrikaans for South Africa, Arabic for Saudi Arabia, Cebuano for the Philippines, Czech for Czech Republic, Danish for Denmark, Dutch for Belgium (Flemish), Dutch for the Netherlands, English for Canada, English for the Philippines, English for the UK, Farsi for Iran, Finnish for Finland, French for Belgium, French for Canada, French for France, French for Switzerland, German for Austria, German for Germany, German for Switzerland, Greek for Greece, Hungarian for Hungary, Italian for Italy, Italian for Switzerland, Japanese for Japan, Korean for Korea, Mandarin for China, Mandarin for Taiwan, Norwegian for Norway, Polish for Poland, Portuguese for Portugal, Russian for Russia, Serbian for Serbia, Slovak for Slovakia, Spanish for Spain, Spanish for the USA, Swedish for Sweden, Tagalog for the Philippines, and Turkish for Turkey.

'Translations: Czech for Czech Republic, Dutch for the Netherlands, Finnish for Finland, German for Austria, German for Germany, Italian for Italy, Polish for Poland, Spanish for Spain, Swedish for Finland, and Swedish for Sweden. 
applied in different populations including movement disorder patients. It is available and validated in many different languages. However, the scale does not provide information on RLS symptom severity during different times of the day or under different circumstances.

\section{Restless Legs Syndrome-6 (RLS-6) Scale Description}

The RLS-6 is a specific measure to assess the severity of RLS that was developed more than a decade ago (55) and has been recently validated (56). This 6 items scale is divided into four domains assessing RLS symptoms during different times and situation of the day (Table 2).

\section{Psychometric Properties}

The RLS-6 has adequate internal consistency (Cronbach's alpha $=0.79$ ). The factor analysis showed one factor explaining $55 \%$ of the variance (item 5 excluded). Moderate to high correlations were obtained between RLS- 6 domains and IRLS subscores (0.25-0.70) and between RLS-6 domains and IRLS total score $(0.35-0.74)$. The RLS-6 displayed a satisfactory ability to discriminate between patients in different severity categories as assessed by the IRLS and CGIS, and was responsive to treatment, with responsiveness coefficients ranging from 0.38 to 0.49 , except for the RLS mimics domain (56).

\section{Data From Different Populations}

The RLS- 6 has been validated in adults of both genders with RLS. To the best of our knowledge, there are no data on other populations, and this scale has not yet been used in movement disorders patients.

\section{Strengths and Limitations}

In a revision of instruments to assess the severity of RLS performed by the MDS Task Force (50), this scale was rated as "suggested," since validation data had not been published. However, validation data are currently available, demonstrating good psychometric properties and good responsiveness (56). It is a complementary scale to be used with the IRLS as it provides information on symptom severity at different times of the day and night and during activities. However, there are no data on its reproducibility and stability.

\section{Augmentation Severity Rating Scale (ASRS) Scale Description}

The ASRS was designed as a quantitative measure of the severity of augmentation (a paradoxical worsening of RLS symptoms from dopaminergic therapy) during clinical studies (57). It consists of 3 items that evaluate where (body part) and when RLS symptoms start and should be administered at baseline (before treatment) and after treatment. The scale has satisfactory sensitivity and specificity values (57) (Table 2 ).

\section{Psychometric Properties}

The ASRS showed acceptable internal consistency (Cronbach's alpha of 0.62). Factor analysis showed only one factor. The worst augmentation score under treatment showed a strong correlation with the independent rating of an expert (0.72), and the ASRS scores were significantly different between subjects with and without augmentation according to experts' opinion. The correlation between the CGIS for augmentation and the ASRS total score was moderate (0.53). Test-retest reliability was satisfactory (0.72); the inter-rater reliability analysis was excellent (0.94) (57).

\section{Data From Different Populations}

It has been validated in an adult population of RLS patients of both genders. No data on patients with other movement disorder and associated RLS are available.

\section{Strengths and Limitations}

The ASRS is a specific tool to measure augmentation in RLS patients who have been treated with dopaminergic agents. In the MDS Task Force review (50), this scale was rated as "recommended" to measure augmentation. The scale must be administered before and after the start of dopaminergic therapy. The main disadvantage is that it has not been correlated with objective measures of augmentation.

\section{Restless Legs Syndrome Quality of Life Instrument (RLS-QLI) \\ Scale Description}

The RLS-QLI is another self-administered questionnaire designed to measures the impact of RLS on HRQoL (58). This 17-item questionnaire is divided into four domains considering impact on daily activities and sleep (Table 2).

\section{Psychometric Properties}

Factor analysis showed 4 factors. The RLS-QLI has satisfactory internal consistency and reliability: for the subscales, Cronbach's alpha was $0.85-0.91$ test-retest reliability coefficients ranged $0.81-0.93$. It showed weak to moderate correlations with SF-36 subscales $(0.26-0.62)$ and moderate-to-strong correlations with the total IRLS score $(-0.71,-0.62)(58)$.

\section{Data From Different Populations}

The RLS-QLI has been validated in adult patients of both genders, without a confirmed diagnosis of RLS. We did not find data regarding its use in other populations.

\section{Strengths and Limitations}

The MDS Task Force (59) rated this scale as "suggested." It showed good psychometric properties; however, it has only been tested in a population without a confirmed diagnosis of RLS, and its responsiveness has not been assessed.

\section{Restless Legs Syndrome Quality of Life Questionnaire/Abetz (ARLSQoL) \\ Scale Description}

ARLSQoL (60) is a self-administered scale to measure the impact of RLS on HRQoL. This 18-item questionnaire is made up of two subscales, one evaluating overall impact and the other assessing different spheres of patients' life (i.e., work, sexual, and social) (Table 2). 


\section{Psychometric Properties}

There is one factor for the 10 items that are grouped in the summary score. The ARLSQoL showed excellent internal consistency (Cronbach's alpha $=0.82-0.92)(60,61)$ and satisfactory stability, with ICCs of $0.79,-0.84$ (60). Correlation coefficients were moderate between the scale summary score and the Mental Component Score of the SF-36 $(r=0.50)$ and with the IRLS $(r=-0.67$ to -0.68). The ARLSQoL was able to distinguish between patients with mild, moderate or severe symptoms according to their reports, between levels of sleep problems assessed by the MOS Sleep Scale and between levels of global health status determined by a CGIS $(60,61)$.

\section{Data From Different Populations}

It has been validated in an adult population of RLS patients of both genders. To the best of our knowledge, no data on other populations are available.

\section{Strengths and Limitations}

This is a quick, easy and self-administered instrument to evaluate HRQoL in RLS. It has shown acceptable psychometric properties. However, its responsiveness has not been evaluated. In the MDS Task Force revision of scales to assess HRQoL in RLS (59), this scale was rated as "recommended."

\section{Kohnen Restless Legs Syndrome Quality of Life Questionnaire (KRLS-QOL) Scale Description}

The Kohnen Restless Legs Syndrome Quality of Life Questionnaire (KRLS-QOL) is a self-administered questionnaire to assess the HRQoL in patients with RLS. This 12-item questionnaire is divided into five domains evaluating the effect of RLS, how they are handled and overall impact (Domain 5) (Table 2) (62).

\section{Psychometric Properties}

The exploratory factor analysis identified two factors explaining $56.85 \%$ of the variance ("Impaired health by symptoms" and "Burden of symptoms"), but the parallel factor analysis advised to consider only one dimension in the scale.

This scale showed acceptable internal consistency and reproducibility (Cronbach's alpha $=0.88$ ). For test-retest reliability, kappa values were $0.43-0.64$ (item 4), and the ICC for the KRLS-QoL Index was 0.73 . The KRLS-QoL showed moderateto-strong correlations with the IRLS total score (0.68) and its subscores (0.50-0.73), moderate to low correlations with the RLS-6 (0.33-0.57), and with the CGI (0.42). KRLS-QoL-Domain 5 had moderate to high correlations with the IRLS total score (0.60) and subscores (0.49-0.59), moderate to low with the RLS-6 (0.26-0.49), and CGIS (0.37). KRLS-QoL Index and Domain 5 significantly increased their scores with increasing RLS severity levels based on the IRLS and CGIS scores (62). Responsiveness parameters (effect size) showed large effect with an effective treatment, and strong correlations with change in other scales (62).

\section{Data From Different Populations}

The KRLS-QoL has been validated in an adult population of RLS patients of both genders. No data on other populations are available.

\section{Strengths and Limitations}

In the review by the MDS Task Force (59), this scale was rated as "suggested" since the validation study had not been published. However, the KRLS-QoL has now been validated and demonstrated good psychometric properties (62), therefore it can be considered a "recommended" instrument to assess the impact of RLS on HRQoL and to measure responsiveness to therapy.

\section{Post-Sleep Questionnaire for RLS (PSQ-RLS) Scale Description}

The PSQ-RLS is a self-administered questionnaire to assess the impact of RLS on sleep and daily functioning (63). This 5-item questionnaire considers number and length of night-time interruptions of sleep due to RLS (Table 2).

\section{Psychometric Properties}

The PSQ-RLS showed a weak to moderate convergent validity with the following related scales: the IRLS (51), the RLSQoL (61), the Profile of Mood States (64), and sleep domains of the MOS Scale (65). In a study, PSQ-RLS scores did not include systematic measurement errors associated with personal attributes (race, gender, and ethnicity), had adequate discriminate validity across RLS severity groups, and showed satisfactory responsiveness in a 3-month treatment period (63).

\section{Data From Different Populations}

The PSQ-RLS has been validated in an adult population of RLS patients of both genders. No data on other populations are available.

\section{Strengths and Limitations}

The PSQ-RLS is an instrument that can be used to assess the impact of RLS on quality of sleep. A review of instruments that assesses HRQoL in RLS (59) noted that the scale had not been used by other investigators beyond its designers and its internal consistency and stability had not been explored, which justified the scale's rating as "listed." Subsequently, the scale has been used by other investigators, but the missing psychometric properties have yet to be published.

\section{Restless Legs Syndrome-Next Day Impact Questionnaire (RLS-NDI)}

The RLS-NDI is a self-administered questionnaire to assess the impact of RLS on sleep and daily functioning. The RLS-NDI is composed of 14 items rated on an 11-point Likert-type scale. It is designed to be administered in the evening with a 12 -h recall, to assess the impact of RLS on the same day. It has shown a good content validity, but no further data on its psychometric properties are available (66).

\section{Pediatric Restless Legs Syndrome Severity Scale (P-RLS-SS)}

The P-RLS-SS was designed to measure RLS severity in children (67). This scale is composed of 41 items (17 morning and 24 evening items) and a parent questionnaire composed of 20 items. Its importance relies in being the only instrument to assess RLS severity in children; however it has not been validated, and no data on its psychometric properties are available. 


\section{Multidomain Scales That Assess RLS}

For PD, there are two multidomain scales that assess the range of non-motor symptoms that are prevalent in this disease, the NMSS (23) and the NMSQuest (68). Both instruments include one item for RLS assessment when the patient is lying down or inactive: item 6 of the NMSS and item 26 of the NMSQuest.

\section{Conclusion}

There are two scales (IRLS and RLS-6) that can be recommended to assess the severity of RLS, since they have the appropriate psychometric properties and have been extensively used. There is a recommended scale (ASRS) to assess the augmentation phenomenon. Two scales (KRLS-QoL and ARLSQoL) can be recommended to assess HRQoL in RLS. There is currently no recommended scale to evaluate RLS in the pediatric population. There are single items on PD-specific multidomain scales that assess RLS but there is insufficient evidence to evaluate their psychometric reliability or clinical applicability. Just one of the discussed scales (IRLS) has been used in several movement disorders.

\section{Periodic Leg Movements (PLMs)}

PLMs are sleep-related movements characterized by a stereotyped and periodic pattern. They are relatively common in the general population, particularly in the elderly (69) and can occur in isolation or be associated with RLS or other movement disorders (70). The golden standard to diagnose PLMs is overnight PSG, and two sets of standards for recording and scoring are available: one by the International Restless Legs Syndrome Study group and the World Association of Sleep Medicine (71); the other by the American Academy of Sleep Medicine (72). As PSG is a cumbersome and costly test, alternative assessment tools are currently under evaluation: leg-worn actigraphy (73), contactless devices to measure movement and respiration during sleep (74) and analysis of electrocardiographic data (75) among others. Currently, there is no available questionnaire or scale to measure PLMs.

\section{Obstructive Sleep Apnea}

Obstructive sleep apnea is a common sleep-related disorder characterized by repetitive episodes of complete or partial collapse of the upper airway which cause breath cessation. Despite being frequently underdiagnosed, its prevalence is reported to be $6-17 \%$, varying according to age, sex, and body mass index (BMI). The gold standard for diagnosis is based on PSG recording of events of apnea (breathing pauses lasting $10 \mathrm{~s}$ or more) and hypopnea (reduction in respiratory airflow, without apnea, associated with oxygen desaturation or arousal from sleep). The apnea-hypopnea index (AHI) per hour is calculated to determine the presence and severity of OSA (based on standard scoring: $\mathrm{AHI}>5$ mild, $\mathrm{AHI}>15$ moderate, $\mathrm{AHI}>30$ severe) (76).

There are three questionnaires that have been designed as screening tools for OSA. The severity of OSA can be assessed by two extensively used generic scales for sleep disorders, and two specific scales have been developed to assess HRQoL in OSA. Scales that assess OSA are summarized in Table 3.

\section{Wisconsin Sleep Questionnaire (WSQ) Scale Description}

The WSQ is a generic questionnaire to investigate snoring, obstructive apnea, and sleeping problems in general (Table 3) $(77,78)$. It is one of the most cited questionnaires for OSA (79). It has a high sensitivity and a low specificity, especially for diagnosing moderate OSA, and an excellent negative predictive value (Table 3) (80).

\section{Psychometric Properties}

The internal consistency in each domain of the scale was satisfactory (Cronbach's alpha $=0.67-0.81$ ), reliability was acceptable: at retest after 3 months, the kappa values were $0.28-0.60$, the Cohen kappa was $>0.60$ (81).

\section{Data From Different Populations}

This scale has been used in the general population and in a sleep disorders population. It has not been used in movement disorders to the best of our knowledge.

\section{Strengths and Limitations}

This is a widely used scale for assessing different aspects of OSA. It has demonstrated robust psychometric properties with a high sensitivity. However, its specificity is low, and it has not been used in movement disorders patients.

\section{Sleep Apnea Scale of the Sleep Disorders Questionnaire (SA-SDQ) \\ Scale Description}

The SA-SDQ is part of a generic questionnaire on sleep disorders, the Sleep Disorders Questionnaire. This subscale includes questions about sleep disturbances and demographic data. The sensitivity and specificity of this scale are acceptable, the negative predictive value was high (Table 3) (82).

\section{Psychometric Properties}

The scale has shown good internal consistency: Cronbach's alpha was 0.85 , and the item-total correlation ranged from 0.19 to 0.71. The intercorrelations with other subscales from the SDQ were weak $(<0.35)$, and the scale could distinguish patients with sleep apnea from patients with other sleep disorders (narcolepsy, periodic limb movements, and psychiatric sleep disorder). The test-retest reliability after 4 months was acceptable (0.84) (82).

\section{Data From Different Populations}

The SA-SDQ has been validated in both genders, in patients with sleep disorders and with epilepsy (83). To the best of our knowledge, there are currently no studies that report its use in movement disorders populations.

\section{Strengths and Limitations}

This scale has satisfactory psychometric properties. It accurately diagnoses patients with sleep apnea events and sleep apnea related conditions. However, no data were found on the responsiveness of this scale and its use in movement disorders. 


\section{Multivariable Apnea Prediction (MAP) Index \\ Scale Description}

The MAP index is a specific instrument used for screening sleep apnea (84) (see Table 3 for details). There is also an objective MAP index, only based on symptom frequency. The index showed acceptable sensitivity with lower specificity for detecting any OSA, and good specificity with poorer sensitivity for detecting severe OSA (85) (Table 3).

\section{Psychometric Properties}

The MAP index showed a moderate correlation with the AHI $(r=0.59)$. The objective MAP showed a strong correlation

TABLE 3 | Scales that evaluate obstructive sleep apnea

\begin{tabular}{|c|c|c|c|c|c|c|}
\hline Scale & Overview & Scoring & $\begin{array}{l}\text { Cut off } \\
\text { Diagnostic accuracy }\end{array}$ & Time frame & Administration & Languages \\
\hline WSQ (77) & $\begin{array}{l}\text { Generic on sleep } \\
\text { disorders } \\
\text { Investigates snoring, } \\
\text { obstructive apnea, } \\
\text { and sleeping problems }\end{array}$ & $\begin{array}{l}32 \text { items. } 10 \text { questions on sleep } \\
\text { disorders due to breathing, } \\
5 \text { questions on sleep disorders, } \\
5 \text { questions on medical history, and } \\
12 \text { questions on life habits. Multiple- } \\
\text { choice responses with different } \\
\text { scoring based on the question }\end{array}$ & $\begin{array}{l}\text { Score of }>3 \text { point for } \\
\text { snoring or choking (78) } \\
\text { In general population } \\
\text { Any OSA stage } \\
\text { Sensitivity 79-95\% } \\
\text { Specificity 46-64\% } \\
\text { PPV 46-28\% } \\
\text { NPV 89-97\% } \\
\text { Moderate OSA } \\
\text { Sensitivity } 87 \% \\
\text { Specificity } 40 \% \\
\text { PPV } 11 \% \\
\text { NPV } 97 \% \\
\text { (80) }\end{array}$ & 3 months (81) & $\begin{array}{l}\text { Self-rated } \\
30 \mathrm{~min}\end{array}$ & $\begin{array}{l}\text { French, English, } \\
\text { and Polish } \\
\text { Scoring instructions } \\
\text { provided by authors } \\
\text { (81) }\end{array}$ \\
\hline SA-SDQ (82) & $\begin{array}{l}\text { Generic scale subscale } \\
\text { Assesses sleep } \\
\text { disturbances due to } \\
\text { sleep apnea and sleep } \\
\text { apnea risk factors }\end{array}$ & $\begin{array}{l}8 \text { questions about sleep disturbances } \\
\text { and } 4 \text { other items related to weight, } \\
\text { smoking status, age, and body } \\
\text { mass index (BMI). Each question } \\
\text { is scored on a scale } 0-5 \text { ( } 0=\text { never, } \\
5=\text { always); the total score } \\
\text { ranges } 0-60\end{array}$ & $\begin{array}{l}\text { In sleep clinic patients } \\
36 \text { for men } \\
32 \text { for women } \\
\text { Sensitivity } 85-88 \% \\
\text { Specificity } 76-81 \% \\
\text { PPV } 31-72 \% \\
\text { NPV } 87-99 \% \\
\text { (82) }\end{array}$ & Lifetime & $\begin{array}{l}\text { Self-rated } \\
8 \mathrm{~min}\end{array}$ & $\begin{array}{l}\text { English and } \\
\text { Dutch }\end{array}$ \\
\hline MAP index (84) & $\begin{array}{l}\text { OSA specific } \\
\text { Screening } \\
\text { questionnaire } \\
\text { for OSA }\end{array}$ & $\begin{array}{l}3 \text { frequency questions (loud } \\
\text { snoring, snoring or gasping, } \\
\text { cessation of breathing, or struggle } \\
\text { for breath) and gender, age, and BMl } \\
\text { are calculated. Formulas are } \\
\text { explained in the reference. MAP } \\
\text { index ranges between } 0 \text { and } 1\end{array}$ & $\begin{array}{l}\text { In sleep clinic patients } \\
\text { Mild OSA [apnea- } \\
\text { hypopnea index }(A H I)=5 \text { ] } \\
\text { Cutoff } 0.46 \\
\text { Sensitivity } 76.8 \% \\
\text { Specificity } 71.8 \% \\
\text { Moderate OSA (AHI = 15) } \\
\text { Cutoff } 0.48 \\
\text { Sensitivity } 83.3 \% \\
\text { Specificity } 64.3 \% \\
\text { Severe OSA (AHI = 30) } \\
\text { Cutoff } 0.65 \\
\text { Sensitivity } 61.8 \% \\
\text { Specificity } 79.2 \% \\
\text { (85) }\end{array}$ & $\begin{array}{l}\text { Last month } \\
\text { and lifetime } \\
\text { risk factors }\end{array}$ & $\begin{array}{l}\text { Self-rated } \\
5 \text { min for the } \\
\text { scale and } 5 \text { min } \\
\text { for scoring }\end{array}$ & English \\
\hline $\begin{array}{l}\text { Berlin } \\
\text { questionnaire (87) }\end{array}$ & $\begin{array}{l}\text { OSA specific } \\
\text { Screening } \\
\text { questionnaire } \\
\text { for OSAS }\end{array}$ & $\begin{array}{l}10 \text { items, } 3 \text { domains: snoring } \\
\text { severity, excessive daytime sleepiness, } \\
\text { history of high blood pressure or } \\
\text { obesity. Multiple-choice questions, } \\
\text { for each question there is different } \\
\text { scoring. Categories } 1 \text { and } 2 \text { are } \\
\text { positive if total score is } \geq 2 \text {; Category } \\
3 \text { is positive if high blood pressure or if } \\
\text { BMl }>30 \mathrm{~kg} / \mathrm{m}^{2} \text {. Scoring: high risk: } \geq 2 \\
\text { categories with positive score; low risk: } \\
1 \text { or no categories with positive score }\end{array}$ & $\begin{array}{l}\text { High risk score in } \\
\text { sleep clinic patients } \\
\text { Sensitivity } 79-82 \% \\
\text { Specificity } 32-39 \% \\
\text { (88) }\end{array}$ & Lifetime & $\begin{array}{l}\text { Self-rated } \\
10 \mathrm{~min}\end{array}$ & $\begin{array}{l}\text { English Arabic, } \\
\text { Chinese, Dutch, } \\
\text { French, Greek, } \\
\text { Indian, Korean, } \\
\text { Malay, Persian, } \\
\text { Portuguese, } \\
\text { Serbian, Thai, } \\
\text { and Turkish }\end{array}$ \\
\hline
\end{tabular}


TABLE 3 | Continued

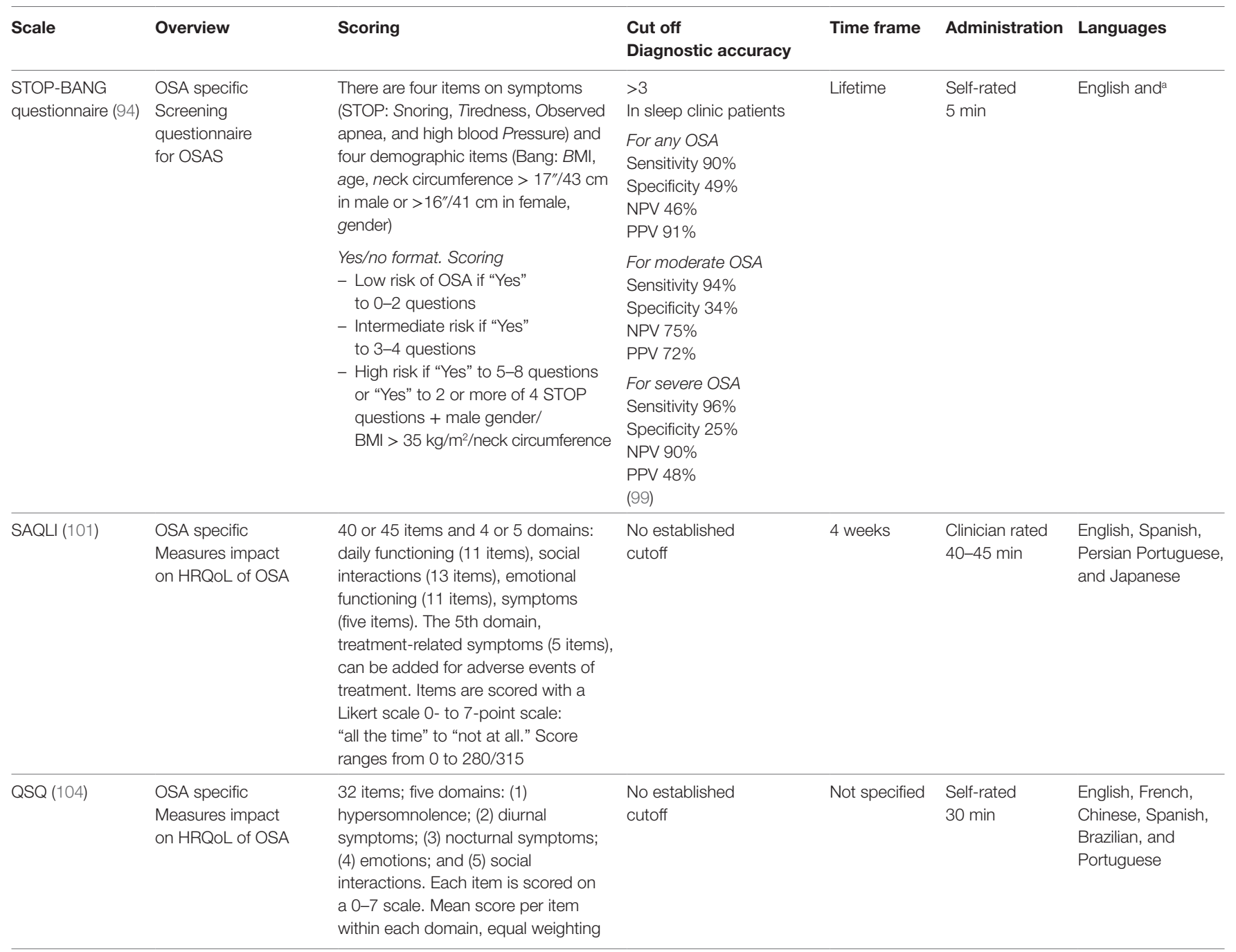

SA-SDQ, Sleep Apnea Scale of the Sleep Disorders Questionnaire; WSQ, Wisconsin Sleep Questionnaire; MAP, Multivariable Apnea Prediction; SAQLI, Calgary Sleep Apnea Quality of Life Index; QSQ, Quebec Sleep Questionnaire; HRQoL, health related quality of life.

${ }^{a}$ Chinese, Persian, Portuguese, Greek, French, Spanish, Afrikaans, Arabic, Bulgarian, Chinese, Czech, Dutch, Filipino, German, Hungarian,

Italian, Korean, Malay, Polish, Romanian, Sami, Taiwanese, Turkish, and Arabic.

with the MAP index, but a poorer correlation with the AHI (85). The MAP index showed good internal consistency (Cronbach's alpha $=0.88-0.93)$, and satisfactory test-retest reliability (84).

\section{Data From Different Populations}

This scale has been used in adults of both genders in a sleep disorder population. To the best of our knowledge, it has not been used in movement disorders.

\section{Strengths and Limitations}

This is a quantitative index to assess the risk of OSA. It has shown good psychometric properties. However, its use is limited since it is not useful in patients with a BMI $>40$ or with mild cognitive impairment $(84,86)$, and there is no experience in movement disorder populations.

\section{Berlin Questionnaire \\ Scale Description}

The Berlin questionnaire (87) is a specific self-administered measure used to screen for sleep apnea that includes 10 items that can be divided into 3 domains. This instrument has shown adequate sensitivity but very low specificity (88) (Table 3).

\section{Psychometric Properties}

This questionnaire has shown satisfactory internal consistency in validation studies for different languages and populations (Cronbach's alpha $=0.68-0.98)$ and acceptable test-retest reliability $0.74-0.98$ (89-92). In the original validation study, the internal consistency was adequate (Cronbach's alpha = 0.86-0.92) (87). 


\section{Data From Different Populations}

The Berlin questionnaire has been validated in different populations including sleep clinic patients, patients before surgery, patients with cerebrovascular diseases/risk factors, multiple sclerosis patients, general population and others $(89,91,93)$. It has also been used in movement disorders populations, in particular: PD, PSP, MSA (13), and Huntington's disease (54).

\section{Strengths and Limitations}

The Berlin questionnaire is an easy and short instrument to screen for OSA. It has been widely used in different populations, including movement disorders populations. It has been translated into different languages. Its limitations include low specificity.

\section{STOP-Bang Questionnaire}

\section{Scale Description}

The STOP-Bang questionnaire is a specific self-administered questionnaire for screening OSA that includes questions about four symptoms and demographic data (94) (Table 3). Other versions of this scale are available: there is a shorter version (4-item STOP Questionnaire), a weighted version (wSTOP-Bang) and a continuous version (cSTOP-Bang) (95).

\section{Psychometric Properties}

In the original validation of the questionnaire, internal consistency was not assessed because the four questions STOP reflected four different dimensions of OSA morbidity (94). However, other investigators validating language version found moderate internal consistency (Cronbach's alpha ranging from 0.62 to 0.7 ) $(96,97)$. Test-retest reliability has been adequate (97) and high $(94,98)$. The STOP-Bang questionnaire has an excellent sensitivity, but a low specificity; showing high positive and negative predictive values (99) (Table 3).

\section{Data From Different Populations}

The STOP-Bang questionnaire has been validated in adult patients in both genders; it has been used to screen for OSA in preoperative clinics, sleep clinics, workers at risk, kidney failure patients and in the general population (99), but, to the best our knowledge, not in movement disorders.

\section{Strengths and Limitations}

The STOP-Bang questionnaire is an easy and short measure to screen for OSA. It has been extensively used in different populations and has been translated into numerous languages. It is highly sensitive, but not specific; specificity can be raised using the continuous version (cSTOP-Bang), adding more variables (e.g., serum bicarbonate level) or modifying the cutoff; however, in the latter case, sensitivity drops drastically $(95,99,100)$.

\section{Calgary Sleep Apnea Quality of Life Index (SAQLI) Scale Description \\ The Calgary SAQLI is a specific, self-administered scale used to measure HRQoL in patients affected by sleep apnea (101). It is a long questionnaire ( 40 or 45 items, if the examiner wants to assess treatment-related symptoms) (Table 3).}

\section{Psychometric Properties}

The scale has satisfactory internal consistency (Cronbach's alpha $=0.88-0.92$ for the total scale and 0.70-91 for the subscales) and high reliability (ICC after 2 weeks $=0.92$ ). The SAQLI showed no correlation with the respiratory disturbance index, a measure of severity of OSA, a weak correlation $(-0.26)$ with the Epworth Sleepiness Scale (ESS), and moderateto-strong correlations $(0.39-0.71)$ with the sleep domains of the SF-36 (102). The SAQLI showed satisfactory responsiveness (103).

\section{Data From Different Populations}

This scale has been used in adults of both genders in a sleep disorder population. It has not been used in movement disorders, to the best of our knowledge.

\section{Strengths and Limitations}

This is a specific scale for assessing HRQoL in OSA. It offers a global evaluation of aspects of life on which OSA can impact, it has good psychometric properties, and it has been translated into different languages. However, this scale showed poor correlation with other measures of sleep apnea, sleep, and quality of life.

\section{Quebec Sleep Questionnaire (QSQ)}

\section{Scale Description}

The QSQ (104) is a specific, self-administered questionnaire that evaluates HRQoL in patients with OSA through 32 questions (Table 3).

\section{Psychometric Properties}

Internal consistency and reliability were satisfactory: Cronbach's alpha was $0.76-0.94$, and the ICC after 7 months ranged from 0.82 to 0.91 in the domains. It showed moderate-to-strong convergent validity with the following scales: Functional Outcomes in Sleep Questionnaire (FOSQ), Symptom Checklist-90, and ESS (-0.64). There was a high correlation with the Beck Depression Inventory (BDI) (104). The scale responsiveness has been assessed in an OSA population undergoing CPAP treatment (104).

\section{Data From Different Populations}

The QSQ was validated in a sleep clinic population, in adult patients of both genders. It has not been used in movement disorders to the best of our knowledge.

\section{Strengths and Limitations}

The QSQ is a fast and specific tool to assess HRQoL in OSA; it showed satisfactory psychometric properties and responsiveness. However, it showed a high correlation with the BDI, which can be a confounding factor. It has not been used in movement disorder patients.

\section{Multidomain Scales That Assess OSA}

The PSQI is a self-rated scale designed to measure generic sleep disturbances (7); items $5 \mathrm{~d}$ and $5 \mathrm{e}$ of the PSQI assess, respectively, the inability to breathe comfortably and the occurrence of loud coughs or snores during sleep in the past month. 


\section{Conclusion}

The Berlin questionnaire is the only scale that has been used in movement disorders populations. This questionnaire has been validated, has shown good psychometric properties, and has been widely used. The STOP-Bang questionnaire has similar characteristics but has not been used in movement disorders. Good psychometric properties have also been identified in another screening questionnaire (MAP index) and severity assessment tools such as the WSQ, SA-SDQ. Both the SAQLI and the QSQ are validated specific questionnaires to assess HRQoL in OSA, but they have not been used in movement disorders.

\section{DIURNAL SLEEP DISORDERS: EDS AND SLEEP ATTACKS}

Other sleep disturbances found in movement disorders affect the waking hours, such as EDS and sleep attacks. EDS is a symptom rather than a primary disease and can be the consequence of sleep deprivation, sleep disturbances as discussed above, medications or substance abuse, metabolic, neurological and psychiatric diseases or, more rarely, narcolepsy. In PD, for example, the pathophysiology of EDS is multifactorial and related to NS disturbances, other causes of sleep fragmentation (motor symptoms, painful dystonia, and dyskinesias), the neurodegenerative process itself and to medications. In fact, dopaminergic agents can disrupt sleep and induce somnolence, and sedation and drowsiness have been reported as adverse events of dopamine agonists (105).

Excessive daytime sleepiness and sleep attacks can be reported by patients or their relatives and can be assessed with self-reported scales or with objective tests such as the MSLT and the MWT. Since these laboratory tests are time consuming and costly, scales have been developed to detect and evaluate the severity of EDS and sleep attacks.

\section{Stanford Sleepiness Scale (SSS) Scale Description}

The SSS is a generic scale that measures the current state of sleepiness $(106,107)$. It is based on a single item rated on a Likert-type scale from 0 to 7 , with higher scores indicating more subjective sleepiness.

\section{Psychometric Characteristics}

Data on the validity and reliability of the scale are sparse (108). The original publication claims high reliability (106). In healthy subjects, sensitivity to change has been reported $(109,110)$. The scale shows no correlation with the ESS which may be expected as the measured constructs are different.

\section{Scale Use in Movement Disorders}

The scale has been used to assess the induction of sleep by levodopa in PD versus MSA (111) and diminished homeostatic sleep drive in PSP (112). To the best of our knowledge, there are no available data in other movement disorders.

\section{Strengths and Limitations}

The SSS is an extensively used scale due to its availability in many languages and simplicity. It is useful for rating the sleepiness state of the individual at the time of testing. The MDS Task Force on sleep disturbances in PD concluded that the SSS is a "suggested" scale for rating sleepiness and to measure severity at a specific moment (10). However, an obvious limitation is the lack of data on psychometric characteristics of the scale.

\section{Epworth Sleepiness Scale Scale Description}

The ESS (113) is a generic scale that measures the risk of falling asleep during daily activities. This scale evaluates the possibility of dozing off in 8 every-day situations. Several cutoff scores with different sensitivities and specificities have been proposed to indicate subjects at higher risk of falling asleep involuntarily (114) (Table 4).

\section{Psychometric Properties}

Internal consistency of the ESS is high (Cronbach's alpha $=0.88$ ), and the scale has demonstrated acceptable reliability $(r=0.56)$. Floor and ceiling effects are practically absent (115). ESS shows adequate convergent validity with sleep latency measured during the MSLT and during overnight PSG (115), as well as SCOPASleep Daytime Sleepiness (SCOPA-Sleep-DS) subscale scores in the PD patients (11).

\section{Scale Use in Movement Disorders}

The ESS has been extensively used in populations with diverse sleep disorders, such as sleep apnea, narcolepsy, and idiopathic hypersomnia $(113,115)$ and idiopathic RBD $(116)$. It also has been widely used in PD (10) and in other hypokinetic disorders such as MSA $(117,118)$. In addition, there is experience with this scale in hyperkinetic disorders such as Huntington's disease (14, 119, 120), dystonia $(19,121,122)$, and essential tremor (123-125).

\section{Strengths and Limitations}

The ESS has adequate psychometric properties and has been extensively used by many groups in diverse movement disorder cohorts to evaluate sleep propensity. It is recommended for screening and evaluating severity of DS in the PD population (10). It has also shown sensitivity to change after intervention. However, the scale does not include information from a caregiver, partner or other outside source; and thus, the information provided may be limited, possibly underestimating risk, since the patient may often be unaware of dozing off. The item "while in the car" is ambiguous since it does not specify whether the person is in the driver or passenger's seat. The EES does not include an item on risk of falling asleep while driving nor does it screen for the risk of sudden sleep attacks.

\section{Inappropriate Sleep Composite Score (ISCS) \\ Scale Description}

Two modified versions of the ESS were proposed by the Canadian Movement Disorders Group to fill the gaps of the previous scale, thus developing the ISCS (114). This scale is made up of 6 items, two from the ESS and four additional new items. If sleepiness 
TABLE 4 | Scales that evaluate excessive daytime sleepiness in movement disorders.

\begin{tabular}{|c|c|c|c|c|c|c|}
\hline Scale & Overview & Scoring & $\begin{array}{l}\text { Cut off } \\
\text { Diagnostic } \\
\text { accuracy }\end{array}$ & Time frame & Administration & Languages \\
\hline SSS (106) & $\begin{array}{l}\text { Generic } \\
\text { Measures current state } \\
\text { of sleepiness }\end{array}$ & 1 item. Seven point Likert-type scale & $\begin{array}{l}\text { No established } \\
\text { cutoff }\end{array}$ & At this time & Self-rated & $\begin{array}{l}\text { Public } \\
\text { English } \\
\text { French } \\
\text { Spanish }\end{array}$ \\
\hline ESS (113) & $\begin{array}{l}\text { Generic } \\
\text { Measures sleep propensity } \\
\text { in daily situations }\end{array}$ & $\begin{array}{l}8 \text { items, rated } 0 \text { (would never doze) to } \\
3 \text { (high chance of dosing). Range of total } \\
\text { score 0-24 }\end{array}$ & $\begin{array}{l}>7 \\
\text { Sensitivity } 75 \% \\
\text { Specificity } 50 \% \\
>10 \\
\text { Sensitivity } 52 \% \\
\text { Specificity } 72 \% \\
(115)\end{array}$ & $\begin{array}{l}\text { Recent times } \\
\text { (1-4 weeks) }\end{array}$ & $\begin{array}{l}\text { Self-rated } \\
8 \mathrm{~min}\end{array}$ & $\begin{array}{l}\text { Public } \\
\text { English } \\
\text { German } \\
\text { Spanish } \\
\text { Chinese }\end{array}$ \\
\hline ISCS (114) & $\begin{array}{l}\text { Generic } \\
\text { Measures sleep propensity and } \\
\text { sleep attacks in active tasks }\end{array}$ & $\begin{array}{l}6 \text { items, rated } 0 \text { (would never doze) to } \\
3 \text { (high chance of dosing). Range 0-18. } \\
\text { Two additional questions regarding } \\
\text { sudden sleep onset and blank spells }\end{array}$ & $>1$ & $\begin{array}{l}\text { Since disease } \\
\text { onset }\end{array}$ & $\begin{array}{l}\text { Externally rated } \\
10 \text { min }\end{array}$ & English \\
\hline $\begin{array}{l}\text { SCOPA-Sleep- } \\
\text { DS (11) }\end{array}$ & $\begin{array}{l}\text { PD specific } \\
\text { Measures sleepiness and possibility } \\
\text { of sleep attacks in daily activities }\end{array}$ & $\begin{array}{l}\text { DS includes } 6 \text { items scored from } \\
0 \text { (never) to } 3 \text { (often). Range 0-18 }\end{array}$ & $\begin{array}{l}>4 \\
\text { Sensitivity } 90 \% \\
\text { Specificity } 82 \%\end{array}$ & Previous month & Self-rated & $\begin{array}{l}\text { Public } \\
\text { Dutch } \\
\text { English } \\
\text { Spanish }\end{array}$ \\
\hline
\end{tabular}

DS, daytime sleepiness; ESS, Epworth Sleepiness Scale; ISCS, Inappropriate Sleep Composite Score; SCOPA, Scales for outcomes in PD; SSS Stanford Sleepiness Scale; SCOPASleep-DS, SCOPA-Sleep Daytime Sleepiness; PD, Parkinson's disease.

is present, the patient is asked if dozing off occurs gradually or unpredictably and about the incidence of blank spells.

\section{Psychometric Properties}

The scale was developed with the objective of evaluating the predictors for sudden-onset sleep, particularly while driving, among patients with PD. It was tested in 638 mild PD patients of whom 420 were currently drivers. There was a high floor and no ceiling effect. Unfortunately, the original article does not provide any validation or reliability data and the scale has not been investigated (although has been used) by other groups.

\section{Strengths and Limitations}

The ISCS assesses the propensity of falling asleep during clearly active situations, such as talking or driving. The MDS Task Force reviewing sleep scales in PD gave this scale the rank of "suggested" to evaluate DS and sleep attacks and recommends its use in conjunction with the ESS (10). The scale has no published psychometric analysis, and terminology may lead to confounders since "sudden blank spells" may be due to sleep attacks, but also to syncope or partial seizures.

\section{SCOPA-Sleep-Daytime Sleepiness subscale}

\section{Scale Description}

The DS subscale of the SCOPA-Sleep scale (11) includes 6 items on unexpected sleep attacks, dozing off in daily situations and difficulty staying awake. Items are scored from 0 to 3 , with total scores ranging from 0 to 18 points where higher scores indicate more severe problems.

\section{Psychometric Properties}

The internal consistency of the SCOPA-Sleep-DS subscale is good (Cronbach's alpha $=0.91-0.75)(11,18)$. The subscale showed robust test-retest scores (ICC $=0.89$ ) (11). Factor analysis revealed that one factor explains $69.1 \%$ of the variance for this subscale. Scores of the SCOPA-Sleep-DS have shown high correlations with the ESS $(r=0.81, p<0.001)(11)$.

\section{Strengths and Limitations}

The DS subscale of the SCOPA-Sleep has strong psychometric properties and has been extensively used, discriminating between subjects and controls and PD patients in different stages. The subscale is a "recommended" tool for screening and for measuring severity of DS and sleep attacks in PD (10). However, sensitivity to change has not been investigated.

\section{PDSS Item 15}

\section{Scale Description}

The PDSS (17) is a PD-specific, 15-item scale that preferentially evaluates NS problems, with one item pertaining to DS: item 15 (Table 1).

\section{Use in Different Movement Disorder Populations}

Besides being extensively used in PD patients, there are also some available data in dystonia patients (19).

\section{Psychometric Properties}

Item 15 on the PDSS considers DS. This single item has shown a strong correlation with SCOPA-Sleep-DS (18) and the ESS in one study (17) and a moderate correlation (0.23) in another study 
(20). Patients scoring low on this item (mean 4.7) have shown abnormal sleep patterns in overnight PSG results (126).

\section{Strengths and Limitations}

This single item has shown strong correlations with longer DS questionnaires and may thus be useful for screening for DS. However, other psychometric properties and diagnostic accuracy have not been tested.

\section{Multidomain Scales to Assess DS}

Some multidomain scales such as the NMSQuest (22), the NMSS (23), and the MDS UPDRS part 1B (24) include a single item that evaluates DS. Item 3 on the NMSS, similarly to item 22 on the NMSQuest, evaluates if the patient dozes off unintentionally during daytime activities such as during meals or watching TV. Item 1.8 is the second item of part $1 \mathrm{~B}$ on the MDS UPDRS considering non-motor symptoms of daily life. The patient indicates whether he/she has had trouble staying awake during the day in the last week. The limitations to the use of these single items are due to unknown psychometric properties, including lack of data regarding correlation with other scales and sensitivity to change.

\section{DISCUSSION}

Sleep disorders are receiving increased attention in movement disorders due to the high impact on patient HRQoL and caregiver burden as well as the growing knowledge of the underlying pathophysiological mechanisms. There are currently multiple questionnaires that can be used to screen and measure the severity of the most frequent sleep problems that affect movement disorder patients, and they have been summarized in this review. Selection of the most appropriate instrument for assessment of insomnia, nocturia, RLS, OSA, and EDS should be guided by the appropriateness of the scale for the objective of the study, availability, psychometric attributes, responsiveness, and previous experience in similar populations. In interpreting the results of questionnaires, the clinician should consider the presence of psychological factors like fatigue, impulsivity or depression that may influence completion, the timing of administration of the scale (for example, on or off state for PD patients) and cognitive impairment (127).

Several gaps have been identified that need to be addressed to adequately research the incidence, prevalence, and severity and impact of sleep disorders in populations with movement disorders.

The majority of available questionnaires are generic instruments with established psychometric properties in the general population but no validity or reliability data available in different movement disorder populations. Generic scales have the disadvantage of potentially not assessing areas of specific interest and may lack sensitivity to detect change in a given disease (128). For example, in evaluating insomnia, the well-established PSQI is currently the best option for patients with movement disorders other than PD (where disease-specific scales are available). However, it does not consider any motor symptoms, such as chorea, dystonia, tics, and other hyperkinetic movements, as well as sensitivity disturbances, such as akathisia, or RLS, that may prevent patients from falling asleep. The paucity of data available in different movement disorders populations for these generic scales is striking. For example, the prevalence of RLS in PD is still controversial due to confounders and overlap of symptoms such as dystonia, akathisia, and sensory symptoms. Validation data of the RLS scales in PD, and other forms of parkinsonism, would be helpful to decide if the current instruments are valid tools or additional measures need to be designed taking into account disease-specific symptoms that may mimic RLS. RLS is probably more frequent in ET (129) and cranio-cervical dystonia (130) than controls; however, none of the current scales have been validated in these populations.

Even in sleep disorders such as insomnia, where there are disease-specific scales for PD that are recommendable, none of them appropriately evaluate common disturbances associated with this disease such as PLMs, or sleep apnea, nor do they address motor akinesia or motor fluctuations during sleep. Most of the available scales do not consider the input of a witness, which is highly valuable in sleep disturbances, since selfperception has been reported to differ from laboratory evidence (131) and neuropsychiatric difficulties may make the patient unreliable.

For RLS evaluation, several unmet needs should be considered. To date, none of the scales that measure severity are selfadministered (unlike those that consider impact on HRQoL), and the scale designed to evaluate the pediatric population still lacks psychometric data, and validity data in different movement disorders are sparse.

Currently, there are no questionnaires or scales designed to address some common sleep disorders in movement disorders such as sun-down confusion, disordered breathing and PLM. Nocturia is one of the most prevalent and bothersome symptoms for patients, yet it is only considered by $1-2$ items in multidomain scales that have not been individually analyzed for their psychometric properties. Similarly, psychometric data on the scales that screen or evaluate the severity of sleep attacks, which can be potentially lethal if the person is driving, manipulating machinery or using a cutting tool, are lacking.

\section{CONCLUSION}

To advance in the research of sleep and movement disorders, scientific methodology based on adequate diagnosis is of key importance. This review covers a number of questionnaires that can aid in the screening and appraisal of the most frequent nocturnal and diurnal sleep disturbances that affect movement disorder patients. However, disease-specific scales are only available for PD and even in this "best case scenario," some prevalent symptoms such as sleep apnea or nocturia are insufficiently addressed. Thus, we recommend the development of movement disorder, condition-specific scales addressing the most important and characteristic sleep disturbances and their correlates as well as the revision of existing movement disorder scales, such as the Unified Multiple System Atrophy Rating Scale or the Unified Huntington's Disease Rating Scale, to add a sleep domain. We also advocate for the development of guidelines to steer adequate 
application of existing instruments, including interpretation of results and significant change due to treatment or other causes, with the objective of improving the management of sleep disturbances in each movement disorder entity. They should include a recommended combination of assessments using different raters (health professional, patient, and caregiver) as well as advice for when further laboratory testing (PSG or MSLT) should be performed.

\section{REFERENCES}

1. Gros P, Videnovic A. Sleep and Circadin rythm disorders in Parkinson's disease. Curr Sleep Med Rep (2017) 3:222-34. doi:10.1007/s40675-0170079-y

2. Abbott SM, Videnovic A. Sleep disorders in atypical Parkinsonism. Mov Disord Clin Pract (2014) 1:89-96. doi:10.1002/mdc3.12025

3. Driver-Dunckley ED, Adler $\mathrm{CH}$. Movement disorders and sleep. Neurol Clin (2012) 30:1345-58. doi:10.1016/j.ncl.2012.08.019

4. Pillai JA, Leverenz JB. Sleep and neurodegeneration. Chest (2017) 151: 1375-86. doi:10.1016/j.chest.2017.01.002

5. Coelho FMS, Narayansingh M, Murray BJ. Testing sleepiness and vigilance in the sleep laboratory. Curr Opin Pulm Med (2011) 17:406-11. doi:10.1097/ MCP.0b013e32834b7e04

6. Buysse DJ. Insomnia. JAMA (2013) 309:706-16. doi:10.1001/jama.2013.193

7. Buysse DJ, Reynolds CF III, Monk TH, Berman SR, Kupfer DJ. The Pittsburgh Sleep Quality Index: a new instrument for psychiatric practice and research. Psychiatry Res (1989) 28:193-213. doi:10.1016/0165-1781 (89)90047-4

8. Backhaus J, Junghanns K, Broocks A, Riemann D, Hohagen F. Test-retest reliability and validity of the Pittsburgh Sleep Quality Index in primary insomnia. J Psychosom Res (2002) 53:737-40. doi:10.1016/S0022-3999 (02)00330-6

9. Carpenter JS, Andrykowski MA. Psychometric evaluation of the Pittsburgh Sleep Quality Index. J Psychosom Res (1998) 45:5-13. doi:10.1016/ S0022-3999(97)00298-5

10. Högl B, Arnulf I, Comella C, Ferreira J, Iranzo A, Tilley B, et al. Scales to assess sleep impairment in Parkinson's disease: critique and recommendations. Mov Disord (2010) 25:2704-16. doi:10.1002/mds.23190

11. Marinus J, Visser M, van Hilten JJ, Lammers GJ, Stiggelbout AM. Assessment of sleep and sleepiness in Parkinson disease. Sleep (2003) 26:1049-54. doi:10.1093/sleep/26.8.1049

12. Mahale R, Yadav R, Pal PK. Quality of sleep in young onset Parkinson's disease: any difference from older onset Parkinson's disease. Parkinsonism Relat Disord (2015) 21:461-4. doi:10.1016/j.parkreldis.2015.02.007

13. Gama RL, Távora DG, Bomfim RC, Silva CE, de Bruin VM, de Bruin PFC. Sleep disturbances and brain MRI morphometry in Parkinson's disease, multiple system atrophy and progressive supranuclear palsy - a comparative study. Parkinsonism Relat Disord (2010) 16:275-9. doi:10.1016/j. parkreldis.2010.01.002

14. Lazar AS, Panin F, Goodman AOG, Lazic SE, Lazar ZI, Mason SL, et al. Sleep deficits but no metabolic deficits in premanifest Huntington's disease. Ann Neurol (2015) 78:630-48. doi:10.1002/ana.24495

15. Iranzo A, Valldeoriola F, Santamaría J, Tolosa E, Rumià J. Sleep symptoms and polysomnographic architecture in advanced Parkinson's disease after chronic bilateral subthalamic stimulation. J Neurol Neurosurg Psychiatry (2002) 72:661-4. doi:10.1136/jnnp.72.5.661

16. Menza M, Dobkin RD, Marin H, Mark MH, Gara M, Buyske S, et al. A controlled trial of antidepressants in patients with Parkinson disease and depression. Neurology (2009) 72:886-92. doi:10.1212/01.wnl.0000336340. 89821.b3

17. Chaudhuri KR, Pal S, DiMarco A, Whately-Smith C, Bridgman K, Mathew R, et al. The Parkinson's disease sleep scale: a new instrument for assessing sleep and nocturnal disability in Parkinson's disease. J Neurol Neurosurg Psychiatry (2002) 73:629-35. doi:10.1136/jnnp.73.6.629

18. Martinez-Martin P, Visser M, Rodriguez-Blazquez C, Marinus J, Chaudhuri KR, van Hilten JJ, et al. SCOPA-sleep and PDSS: two scales for assessment of sleep

\section{AUTHOR CONTRIBUTIONS}

MK: conception and design, drafting of manuscript, interpretation of data, and revision of the manuscript. RB: drafting of manuscript and interpretation of data. CR-B and MF: interpretation of data and critical revision of the manuscript. PM-M: conception and design, interpretation of data, and critical revision of the manuscript.

disorder in Parkinson's disease. Mov Disord (2008) 23:1681-8. doi:10.1002/ mds. 22110

19. Wagle Shukla A, Brown R, Heese K, Jones J, Rodriguez RL, Malaty IM, et al. High rates of fatigue and sleep disturbances in dystonia. Int J Neurosci (2016) 126:928-35. doi:10.3109/00207454.2015.1085035

20. Martínez-Martín P, Salvador C, Menéndez-Guisasola L, González S, Tobías A, Almazán J, et al. Parkinson's disease sleep scale: validation study of a Spanish version. Mov Disord (2004) 19:1226-32. doi:10.1002/mds.20144

21. Trenkwalder C, Kohnen R, Högl B, Metta V, Sixel-Döring F, Frauscher B, et al. Parkinson's disease sleep scale-validation of the revised version PDSS-2. Mov Disord (2011) 26:644-52. doi:10.1002/mds.23476

22. Chaudhuri KR, Martinez-Martin P, Schapira AH, Stocchi F, Sethi K, Odin P, et al. International multicenter pilot study of the first comprehensive self-completed nonmotor symptoms questionnaire for Parkinson's disease: the NMSQuest study. Mov Disord (2006) 21:916-23. doi:10.1002/ mds. 20844

23. Chaudhuri KR, Martinez-Martin P, Brown RG, Sethi K, Stocchi F, Odin P, et al. The metric properties of a novel non-motor symptoms scale for Parkinson's disease: results from an international pilot study. Mov Disord (2007) 22:1901-11. doi:10.1002/mds.21596

24. Goetz CG, Tilley BC, Shaftman SR, Stebbins GT, Fahn S, Martinez-Martin P, et al. Movement Disorder Society-sponsored revision of the Unified Parkinson's Disease Rating Scale (MDS-UPDRS): scale presentation and clinimetric testing results. Mov Disord (2008) 23:2129-70. doi:10.1002/ mds. 22340

25. Lee C-N, Kim M, Lee HM, Jang J-W, Lee S-M, Kwon D-Y, et al. The interrelationship between non-motor symptoms in atypical Parkinsonism. J Neurol Sci (2013) 327:15-21. doi:10.1016/j.jns.2013.01.034

26. Hall DA, Forjaz MJ, Golbe LI, Litvan I, Payan CAM, Goetz CG, et al. Scales to assess clinical features of progressive supranuclear palsy: MDS task force report. Mov Disord Clin Pract (2015) 2:127-34. doi:10.1002/ mdc3.12130

27. Fine ND, Weiss JP, Wein AJ. Nocturia: consequences, classification, and management. F1000Res (2017) 6:1627. doi:10.12688/f1000research.11979.1

28. Schapira AHV, Chaudhuri KR, Jenner P. Non-motor features of Parkinson disease. Nat Rev Neurosci (2017) 18:435-50. doi:10.1038/nrn.2017.62

29. Coyne K, Revicki D, Hunt T, Corey R, Stewart W, Bentkover J, et al. Psychometric validation of an overactive bladder symptom and healthrelated quality of life questionnaire: the OAB-q. Qual Life Res (2002) 11:563-74. doi:10.1023/A:1016370925601

30. Coyne KS, Thompson CL, Lai J-S, Sexton CC. An overactive bladder symptom and health-related quality of life short-form: validation of the OAB-q SF. Neurourol Urodyn (2015) 34:255-63. doi:10.1002/nau.22559

31. Matza LS, Thompson CL, Krasnow J, Brewster-Jordan J, Zyczynski T, Coyne KS. Test-retest reliability of four questionnaires for patients with overactive bladder: the overactive bladder questionnaire (OAB-q), patient perception of bladder condition (PPBC), urgency questionnaire (UQ), and the primary OAB symptom questionnaire (POSQ). Neurourol Urodyn (2005) 24:215-25. doi: $10.1002 /$ nau. 20110

32. Coyne KS, Matza LS, Thompson CL. The responsiveness of the overactive bladder questionnaire (OAB-q). Qual Life Res (2005) 14:849-55. doi:10.1007/ s11136-004-0706-1

33. Iacovelli E, Gilio F, Meco G, Fattapposta F, Vanacore N, Brusa L, et al. Bladder symptoms assessed with overactive bladder questionnaire in Parkinson's disease. Mov Disord (2010) 25:1203-9. doi:10.1002/mds.23093

34. Kabay S, Canbaz Kabay S, Cetiner M, Mestan E, Sevim M, Ayas S, et al. The clinical and urodynamic results of percutaneous posterior tibial nerve 
stimulation on neurogenic detrusor overactivity in patients with Parkinson's disease. Urology (2016) 87:76-81. doi:10.1016/j.urology.2015.09.026

35. Homma Y, Yoshida M, Seki N, Yokoyama O, Kakizaki H, Gotoh M, et al. Symptom assessment tool for overactive bladder syndrome - overactive bladder symptom score. Urology (2006) 68:318-23. doi:10.1016/j.urology. 2006.02.042

36. Mito Y, Yabe I, Yaguchi H, Tajima Y. Urinary dysfunction and motor symptoms in untreated Parkinson's disease. J Neurol Sci (2016) 365:147-50. doi:10.1016/j.jns.2016.04.031

37. Sakushima K, Yamazaki S, Fukuma S, Hayashino Y, Yabe I, Fukuhara S, et al. Influence of urinary urgency and other urinary disturbances on falls in Parkinson’s disease. J Neurol Sci (2016) 360:153-7. doi:10.1016/j.jns.2015. 11.055

38. Haab F, Richard F, Amarenco G, Coloby P, Arnould B, Benmedjahed K, et al. Prostatic diseases and male voiding dysfunction comprehensive evaluation of bladder and urethral dysfunction symptoms: development and psychometric validation of the Urinary Symptom Profile (USP) questionnaire. Urology (2008) 71:646-56. doi:10.1016/j.urology.2007.11.100

39. Batla A, Pareés I, Edwards MJ, Stamelou M, Bhatia KP, Panicker JN. Lower urinary tract dysfunction in patients with functional movement disorders. J Neurol Sci (2016) 361:192-4. doi:10.1016/j.jns.2015.12.048

40. Barry MJ, Fowler FJ, O'Leary MP, Bruskewitz RC, Holtgrewe HL, Mebust WK, et al. The American Urological Association symptom index for benign prostatic hyperplasia. The Measurement Committee of the American Urological Association. J Urol (1992) 148:1549-57; discussion 1564. doi:10.1016/ S0022-5347(17)36966-5

41. Hald T, Nordling J, Andersen JT, Bilde T, Meyhoff HH, Walter S. A patient weighted symptom score system in the evaluation of uncomplicated benign prostatic hyperplasia. Scand J Urol Nephrol Suppl (1991) 138:59-62.

42. Donovan JL, Abrams P, Peters TJ, Kay HE, Reynard J, Chapple C, et al. The ICS-'BPH' Study: the psychometric validity and reliability of the ICSmale questionnaire. Br JUrol (1996) 77:554-62. doi:10.1046/j.1464-410X.1996. 93013.x

43. Donovan JL, Peters TJ, Abrams P, Brookes ST, de aa Rosette JJ, Schäfer W. Scoring the short form ICSmaleSF questionnaire. International Continence Society. J Urol (2000) 164:1948-55. doi:10.1016/S0022-5347(05)66926-1

44. Kolenc M, Moharić M, Kobal J, Podnar S. Bladder dysfunction in presymptomatic gene carriers and patients with Huntington's disease. J Neurol (2014) 261:2360-9. doi:10.1007/s00415-014-7494-5

45. Visser M, Marinus J, Stiggelbout AM, Van Hilten JJ. Assessment of autonomic dysfunction in Parkinson's disease: the SCOPA-AUT. Mov Disord (2004) 19:1306-12. doi:10.1002/mds.20153

46. Picchietti MA, Picchietti DL. Restless legs syndrome and periodic limb movement disorder in children and adolescents. Semin Pediatr Neurol (2008) 15:91-9. doi:10.1016/j.spen.2008.03.005

47. Stevens MS. Restless legs syndrome/Willis-Ekbom disease morbidity: burden, quality of life, cardiovascular aspects, and sleep. Sleep Med Clin (2015) 10:369-73. doi:10.1016/j.jsmc.2015.05.017

48. Allen RP, Picchietti DL, Garcia-Borreguero D, Ondo WG, Walters AS, Winkelman JW, et al. Restless legs syndrome/Willis-Ekbom disease diagnostic criteria: updated International Restless Legs Syndrome Study Group (IRLSSG) consensus criteria - history, rationale, description, and significance. Sleep Med (2014) 15:860-73. doi:10.1016/j.sleep.2014.03.025

49. Allen RP, Earley CJ. Validation of the Johns Hopkins restless legs severity scale. Sleep Med (2001) 2:239-42. doi:10.1016/S1389-9457(00)00080-0

50. Walters AS, Frauscher B, Allen R, Benes H, Chaudhuri KR, GarciaBorreguero D, et al. Review of severity rating scales for restless legs syndrome: critique and recommendations. Mov Disord Clin Pract (2014) 1:317-24. doi: $10.1002 / \mathrm{mdc} 3.12088$

51. Walters AS, LeBrocq C, Dhar A, Hening W, Rosen R, Allen RP, et al. Validation of the International Restless Legs Syndrome Study Group rating scale for restless legs syndrome. Sleep Med (2003) 4:121-32. doi:10.1016/ S1389-9457(02)00258-7

52. Abetz L, Arbuckle R, Allen RP, Garcia-Borreguero D, Hening W, Walters AS, et al. The reliability, validity and responsiveness of the International Restless Legs Syndrome Study Group rating scale and subscales in a clinical-trial setting. Sleep Med (2006) 7:340-9. doi:10.1016/j.sleep.2005.12.011

53. Bhalsing K, Suresh K, Muthane UB, Pal PK. Prevalence and profile of restless legs syndrome in Parkinson's disease and other neurodegenerative disorders: a case-control study. Parkinsonism Relat Disord (2013) 19:426-30. doi:10.1016/j.parkreldis.2012.12.005

54. Piano C, Della Marca G, Losurdo A, Imperatori C, Solito M, CalandraBuonaura G, et al. Subjective assessment of sleep in Huntington disease: reliability of sleep questionnaires compared to polysomnography. Neurodegener Dis (2017) 17:330-7. doi:10.1159/000480701

55. Kohnen R, Oertel W, Stiasny-Kolster K, Benes H, Trenkwalder C. Severity rating of restless legs syndrome: validation of the RLS-6 [abstract suppl]. Sleep (2004) 27:A304.

56. Kohnen R, Martinez-Martin P, Benes H, Trenkwalder C, Högl B, Dunkl E, et al. Rating of daytime and nighttime symptoms in RLS: validation of the RLS-6 scale of restless legs syndrome/Willis-Ekbom disease. Sleep Med (2016) 20:116-22. doi:10.1016/j.sleep.2015.10.014

57. García-Borreguero D, Kohnen R, Högl B, Ferini-Strambi L, Hadjigeorgiou GM, Hornyak M, et al. Validation of the Augmentation Severity Rating Scale (ASRS): a multicentric, prospective study with levodopa on restless legs syndrome. Sleep Med (2007) 8:455-63. doi:10.1016/j.sleep.2007.03.023

58. Atkinson MJ, Allen RP, DuChane J, Murray C, Kushida C, Roth T, et al. Validation of the restless legs syndrome quality of life instrument (RLS-QLI): findings of a Consortium of National Experts and the RLS Foundation. Qual Life Res (2004) 13:679-93. doi:10.1023/B:QURE.0000021322.22011.d0

59. Walters AS, Frauscher B, Allen R, Benes H, Chaudhuri KR, GarciaBorreguero D, et al. Review of quality of life instruments for the restless legs syndrome/Willis-Ekbom Disease (RLS/WED): critique and recommendations. J Clin Sleep Med (2014) 10:1351-7. doi:10.5664/jcsm.4300

60. Abetz L, Arbuckle R, Allen RP, Mavraki E, Kirsch J. The reliability, validity and responsiveness of the restless legs syndrome quality of life questionnaire (RLSQoL) in a trial population. Health Qual Life Outcomes (2005) 3:79. doi:10.1186/1477-7525-3-79

61. Abetz L, Vallow SM, Kirsch J, Allen RP, Washburn T, Earley CJ. Validation of the restless legs syndrome quality of life questionnaire. Value Health (2005) 8:157-67. doi:10.1111/j.1524-4733.2005.03010.x

62. Kohnen R, Martinez-Martin P, Benes H, Trenkwalder C, Högl B, Dunkl E, et al. Validation of the Kohnen restless legs syndrome-quality of life instrument. Sleep Med (2016) 24:10-7. doi:10.1016/j.sleep.2016.04.019

63. Canafax DM, Bhanegaonkar A, Bharmal M, Calloway M. Validation of the post sleep questionnaire for assessing subjects with restless legs syndrome: results from two double-blind, multicenter, placebo-controlled clinical trials. BMC Neurol (2011) 11:48. doi:10.1186/1471-2377-11-48

64. Curran LS, Michael AA, Jamie SL. Short form of the Profile of Mood States (POMS-SF): psychometric information. Psychol Assess (1995) 7:80-3. doi:10.1037/1040-3590.7.1.80

65. Allen RP, Kosinski M, Hill-Zabala CE, Calloway MO. Psychometric evaluation and tests of validity of the Medical Outcomes Study 12-item Sleep Scale (MOS sleep). Sleep Med (2009) 10:531-9. doi:10.1016/j.sleep.2008.06.003

66. Lasch KE, Abraham L, Patrick J, Piault EC, Tully SE, Treglia M. Development of a next day functioning measure to assess the impact of sleep disturbance due to restless legs syndrome: the restless legs syndrome-next day impact questionnaire. Sleep Med (2011) 12:754-61. doi:10.1016/j.sleep.2011.03.015

67. Arbuckle R, Abetz L, Durmer JS, Ivanenko A, Owens JA, Croenlein J, et al. Development of the Pediatric Restless Legs Syndrome Severity Scale (P-RLS-SS)@: a patient-reported outcome measure of pediatric RLS symptoms and impact. Sleep Med (2010) 11:897-906. doi:10.1016/j.sleep.2010. 03.016

68. Chaudhuri KR, Healy DG, Schapira AH; National Institute for Clinical Excellence. Non-motor symptoms of Parkinson's disease: diagnosis and management.Lancet Neurol (2006) 5:235-45.doi:10.1016/S1474-4422(06)70373-8

69. Figorilli M, Puligheddu M, Congiu P, Ferri R. The clinical importance of periodic leg movements in sleep. Curr Treat Options Neurol (2017) 19:10. doi:10.1007/s11940-017-0446-5

70. Högl B, Stefani A. Restless legs syndrome and periodic leg movements in patients with movement disorders: specific considerations. Mov Disord (2017) 32:669-81. doi:10.1002/mds.26929

71. Ferri R, Fulda S, Allen RP, Zucconi M, Bruni O, Chokroverty S, et al. World Association of Sleep Medicine (WASM) 2016 standards for recording and scoring leg movements in polysomnograms developed by a joint Task Force from the International and the European Restless Legs Syndrome Study Groups (IRLSSG and EURLSSG). Sleep Med (2016) 26:86-95. doi:10.1016/j. sleep.2016.10.010 
72. Berry RB, Budhiraja R, Gottlieb DJ, Gozal D, Iber C, Kapur VK, et al. Rules for scoring respiratory events in sleep: update of the 2007 AASM manual for the scoring of sleep and associated events. J Clin Sleep Med (2012) 8:597-619. doi:10.5664/jcsm.2172

73. Plante DT. Leg actigraphy to quantify periodic limb movements of sleep: a systematic review and meta-analysis. Sleep Med Rev (2014) 18:425-34. doi:10.1016/j.smrv.2014.02.004

74. Weinreich G, Terjung S, Wang Y, Werther S, Zaffaroni A, Teschler H. Validation of a non-contact screening device for the combination of sleep-disordered breathing and periodic limb movements in sleep. Sleep Breath (2017) 22(1):131-8. doi:10.1007/s11325-017-1546-x

75. Kolappan S, Krishnan S, Murray BJ, Boulos MI. A low-cost approach for wide-spread screening of periodic leg movements related to sleep disorders. 2017 IEEE Canada International Humanitarian Technology Conference (IHTC). Toronto, ON (2017). p. 105-8.

76. Mannarino MR, Di Filippo F, Pirro M. Obstructive sleep apnea syndrome. Eur J Intern Med (2012) 23:586-93. doi:10.1016/j.ejim.2012.05.013

77. Young T, Palta M, Dempsey J, Skatrud J, Weber S, Badr S, et al. The occurrence of sleep-disordered breathing among middle-aged adults. $N$ Engl J Med (1993) 328:1230-5. doi:10.1056/NEJM199304293281704

78. Sharma SK, Kumpawat S, Banga A, Goel A. Prevalence and risk factors of obstructive sleep apnea syndrome in a population of Delhi, India. Chest (2006) 130:149-56. doi:10.1378/chest.130.1.149

79. Fedson AC, Pack AI, Gislason T. Frequently used sleep questionnaires in epidemiological and genetic research for obstructive sleep apnea: a review. Sleep Med Rev (2012) 16:529-37. doi:10.1016/j.smrv.2011.12.002

80. Abrishami A, Khajehdehi A, Chung F. A systematic review of screening questionnaires for obstructive sleep apnea. Can J Anesth (2010) 57:423-38. doi:10.1007/s12630-010-9280-x

81. Teculescu D, Guillemin F, Virion J-M, Aubry C, Hannhart B, Michaely J-P, et al. Reliability of the Wisconsin Sleep Questionnaire: a French contribution to international validation. J Clin Epidemiol (2003) 56:436-40. doi:10.1016/ S0895-4356(03)00029-5

82. Douglass AB, Bornstein R, Nino-Murcia G, Keenan S, Miles L, Zarcone VP, et al. The Sleep Disorders Questionnaire. I: creation and multivariate structure of SDQ. Sleep (1994) 17:160-7. doi:10.1093/sleep/17.2.160

83. Weatherwax KJ, Lin X, Marzec ML, Malow BA. Obstructive sleep apnea in epilepsy patients: the Sleep Apnea scale of the Sleep Disorders Questionnaire (SA-SDQ) is a useful screening instrument for obstructive sleep apnea in a disease-specific population. Sleep Med (2003) 4:517-21. doi:10.1016/j. sleep.2003.07.004

84. Maislin G, Pack AI, Kribbs NB, Smith PL, Schwartz AR, Kline LR, et al. A survey screen for prediction of apnea. Sleep (1995) 18:158-66. doi:10.1093/ sleep/18.3.158

85. Khajeh-Mehrizi A, Aminian O. Diagnostic accuracy of the multivariable apnea prediction (MAP) index as a screening tool for obstructive sleep apnea. J Sleep Sci (2015) 1(1):8-12.

86. Wilson G, Terpening Z, Wong K, Grunstein R, Norrie L, Lewis SJG, et al. Screening for sleep apnea in mild cognitive impairment: the utility of the multivariable apnoea prediction index. Sleep Disord (2014) 2014:945287. doi:10.1155/2014/945287

87. Netzer NC, Stoohs RA, Netzer CM, Clark K, Strohl KP. Using the Berlin questionnaire to identify patients at risk for the sleep apnea syndrome. Ann Intern Med (1999) 131:485-91. doi:10.7326/0003-4819-131-7-19991005000002

88. Senaratna CV, Perret JL, Matheson MC, Lodge CJ, Lowe AJ, Cassim R, et al. Validity of the Berlin questionnaire in detecting obstructive sleep apnea: a systematic review and meta-analysis. Sleep Med Rev (2017) 36:116-24. doi:10.1016/j.smrv.2017.04.001

89. Chung F, Yegneswaran B, Liao P, Chung SA, Vairavanathan S, Islam S, et al. Validation of the Berlin questionnaire and American Society of Anesthesiologists checklist as screening tools for obstructive sleep apnea in surgical patients. Anesthesiology (2008) 108:822-30. doi:10.1097/ALN. 0b013e31816d91b5

90. Popević MB, Milovanović AAPS, Nagorni-Obradović L, Nešić D, Milovanović J, Milovanović AAPS. Screening commercial drivers for obstructive sleep apnea: translation and validation of Serbian version of Berlin questionnaire. Qual Life Res (2016) 25:343-9. doi:10.1007/s11136-015-1087-3
91. Saengsuwan JJ, Ungtrakul N, Saengsuwan JJ, Sawanyawisuth K. Preliminary validity and reliability of a Thai Berlin questionnaire in stroke patients. BMC Res Notes (2014) 7:348. doi:10.1186/1756-0500-7-348

92. Suksakorn S, Rattanaumpawan P, Banhiran W, Cherakul N, Chotinaiwattarakul W. Reliability and validity of a Thai version of the Berlin questionnaire in patients with sleep disordered breathing. J Med Assoc Thai (2014) 97(Suppl 3): S46-56.

93. Nociti V, Losavio FA, Gnoni V, Losurdo A, Testani E, Vollono C, et al. Sleep and fatigue in multiple sclerosis: a questionnaire-based, crosssectional, cohort study. J Neurol Sci (2017) 372:387-92. doi:10.1016/j.jns. 2016.10.040

94. Chung F, Yegneswaran B, Liao P, Chung SA, Vairavanathan S, Islam S, et al. STOP questionnaire: a tool to screen patients for obstructive sleep apnea Anesthesiology (2008) 108:812-21. doi:10.1097/ALN.0b013e31816d83e4

95. Nahapetian R, Silva GE, Vana KD, Parthasarathy S, Quan SF. Weighted STOP-Bang and screening for sleep-disordered breathing. Sleep Breath (2016) 20:597-603. doi:10.1007/s11325-015-1255-2

96. Fonseca LB, Silveira EA, Lima NM, Rabahi MF. STOP-Bang Questionnaire: translation to Portuguese and cross-cultural adaptation for use in Brazil. J Bras Pneumol (2016) 42:266-72. doi:10.1590/s1806-37562015000000243

97. BaHammam AS, Al-Aqeel AM, Alhedyani AA, Al-Obaid GI, Al-Owais MM, Olaish AH. The validity and reliability of an Arabic version of the STOPBang Questionnaire for identifying obstructive sleep apnea. Open Respir Med J (2015) 9:22-9. doi:10.2174/1874306401509010022

98. Popević MB, Milovanović AAPS, Nagorni-Obradović L, Nešić D, Milovanović J, Milovanović AAPS. Screening commercial drivers for obstructive sleep apnea: validation of STOP-Bang Questionnaire. Int J Occup Med Environ Health (2017) 30:751-61. doi:10.13075/ijomeh.1896.00906

99. Nagappa M, Liao P, Wong J, Auckley D, Ramachandran SK, Memtsoudis S, et al. Validation of the STOP-Bang Questionnaire as a screening tool for obstructive sleep apnea among different populations: a systematic review and meta-analysis. PLoS One (2015) 10:e0143697. doi:10.1371/journal.pone. 0143697

100. Chung F, Chau E, Yang Y, Liao P, Hall R, Mokhlesi B. Serum bicarbonate level improves specificity of STOP-Bang screening for obstructive sleep apnea. Chest (2013) 143:1284-93. doi:10.1378/chest.12-1132

101. Flemons WW, Reimer MA. Development of a disease-specific health-related quality of life questionnaire for sleep apnea. Am J Respir Crit Care Med (1998) 158:494-503. doi:10.1164/ajrccm.158.2.9712036

102. Flemons WW, Reimer MA. Measurement properties of the Calgary sleep apnea quality of life index. Am J Respir Crit Care Med (2002) 165:159-64. doi:10.1164/ajrccm.165.2.2010008

103. Billings ME, Rosen CL, Auckley D, Benca R, Foldvary-Schaefer N, Iber C, et al. Psychometric performance and responsiveness of the functional outcomes of sleep questionnaire and sleep apnea quality of life index in a randomized trial: the HomePAP study. Sleep (2014) 37:2017-24. doi:10.5665/ sleep. 4262

104. Lacasse Y, Bureau M, Series F. A new standardised and self-administered quality of life questionnaire specific to obstructive sleep apnoea. Thorax (2004) 59:494-9. doi:10.1136/thx.2003.011205

105. Rye DB. Excessive daytime sleepiness and unintended sleep in Parkinson's disease. Curr Neurol Neurosci Rep (2006) 6:169-76. doi:10.1007/s11910996-0041-8

106. Hoddes E, Dement W, Zarcone V. The development and use of the Stanford Sleepiness Scale (SSS). Psychophysiology (1972) 9:150.

107. Hoddes E, Zarcone V, Smythe H, Phillips R, Dement WC. Quantification of sleepiness: a new approach. Psychophysiology (1973) 10:431-6. doi:10.1111/j. 1469-8986.1973.tb00801.x

108. Maclean AW, Fekken GC, Saskin P, Knowles JB. Psychometric evaluation of the Stanford Sleepiness Scale. J Sleep Res (1992) 1:35-9. doi:10.1111/j. 1365-2869.1992.tb00006.x

109. Herscovitch J, Broughton R. Sensitivity of the stanford sleepiness scale to the effects of cumulative partial sleep deprivation and recovery oversleeping. Sleep (1981) 4:83-91. doi:10.1093/sleep/4.1.83

110. Slanger TE, Gross JV, Pinger A, Morfeld P, Bellinger M, Duhme A-L, et al. Person-directed, non-pharmacological interventions for sleepiness at work and sleep disturbances caused by shift work. Cochrane Database Syst Rev (2016) 8:CD010641. doi:10.1002/14651858.CD010641.pub2 
111. Seppi K, Högl B, Diem A, Peralta C, Wenning GK, Poewe W. Levodopainduced sleepiness in the Parkinson variant of multiple system atrophy. Mov Disord (2006) 21:1281-3. doi:10.1002/mds.20898

112. Walsh CM, Ruoff L, Walker K, Emery A, Varbel J, Karageorgiou E, et al. Sleepless night and day, the plight of progressive supranuclear palsy. Sleep (2017) 40. doi:10.1093/sleep/zsx154

113. Johns MW. A new method for measuring daytime sleepiness: the Epworth sleepiness scale. Sleep (1991) 14:540-5. doi:10.1093/sleep/14.6.540

114. Hobson DE, Lang AE, Martin WRW, Razmy A, Rivest J, Fleming J. Excessive daytime sleepiness and sudden-onset sleep in Parkinson disease: a survey by the Canadian Movement Disorders Group. JAMA (2002) 287:455-63. doi:10.1001/jama.287.4.455

115. Johns MW. Sleepiness in different situations measured by the Epworth Sleepiness Scale. Sleep (1994) 17:703-10. doi:10.1093/sleep/17.8.703

116. Arnulf I, Neutel D, Herlin B, Golmard J-L, Leu-Semenescu S, Cochen de Cock V, et al. Sleepiness in idiopathic REM sleep behavior disorder and Parkinson disease. Sleep (2015) 38:1529-35. doi:10.5665/sleep.5040

117. Moreno-López C, Santamaría J, Salamero M, Del Sorbo F, Albanese A, Pellecchia MT, et al. Excessive daytime sleepiness in multiple system atrophy (SLEEMSA Study). Arch Neurol (2011) 68:223-30. doi:10.1001/archneurol.2010.359

118. Shimohata T, Nakayama H, Tomita M, Ozawa T, Nishizawa M. Daytime sleepiness in Japanese patients with multiple system atrophy: prevalence and determinants. BMCNeurol (2012) 12:130. doi:10.1186/1471-2377-12-130

119. Piano C, Losurdo A, Della Marca G, Solito M, Calandra-Buonaura G, Provini F, et al. Polysomnographic findings and clinical correlates in Huntington disease: a cross-sectional cohort study. Sleep (2015) 38:1489-95. doi: $10.5665 /$ sleep.4996

120. Hurelbrink CB, Lewis SJG, Barker RA. The use of the Actiwatch-Neurologica ${ }^{\circledR}$ system to objectively assess the involuntary movements and sleep-wake activity in patients with mild-moderate Huntington's disease. J Neurol (2005) 252:642-7. doi:10.1007/s00415-005-0709-z

121. Avanzino L, Martino D, Marchese R, Aniello MS, Minafra B, Superbo M, et al. Quality of sleep in primary focal dystonia: a case-control study. Eur J Neurol (2010) 17:576-81. doi:10.1111/j.1468-1331.2009.02884.x

122. Trotti LM, Esper CD, Feustel PJ, Bliwise DL, Factor SA. Excessive daytime sleepiness in cervical dystonia. Parkinsonism Relat Disord (2009) 15:784-6. doi:10.1016/j.parkreldis.2009.04.007

123. Gerbin M, Viner AS, Louis ED. Sleep in essential tremor: a comparison with normal controls and Parkinson's disease patients. Parkinsonism Relat Disord (2012) 18:279-84. doi:10.1016/j.parkreldis.2011.11.004
124. Rohl B, Collins K, Morgan S, Cosentino S, Huey ED, Louis ED. Daytime sleepiness and nighttime sleep quality across the full spectrum of cognitive presentations in essential tremor. J Neurol Sci (2016) 371:24-31. doi:10.1016/j. jns.2016.10.006

125. Chandran V, Pal PK, Reddy JYC, Thennarasu K, Yadav R, Shivashankar N. Non-motor features in essential tremor. Acta Neurol Scand (2012) 125:332-7. doi:10.1111/j.1600-0404.2011.01573.x

126. Dhawan V, Dhoat S, Williams AJ, Dimarco A, Pal S, Forbes A, et al. The range and nature of sleep dysfunction in untreated Parkinson's disease (PD). A comparative controlled clinical study using the Parkinson's disease sleep scale and selective polysomnography. J Neurol Sci (2006) 248:158-62. doi:10.1016/j.jns.2006.05.004

127. Martinez-MartinP,Rodriguez-BlazquezC,ForjazMJ,KurtisMM,SkorvanekM. Measurement of nonmotor symptoms in clinical practice. Int Rev Neurobiol (2017) 133:291-345. doi:10.1016/bs.irn.2017.04.001

128. Martinez-Martin P, Kurtis MM. Health-related quality of life as an outcome variable in Parkinson's disease. Ther Adv Neurol Disord (2012) 105-17. doi:10.1177/1756285611431974

129. Ondo WG, Lai D. Association between restless legs syndrome and essential tremor. Mov Disord (2006) 21:515-8. doi:10.1002/mds.20746

130. Paus S, Gross J, Moll-Müller M, Hentschel F, Spottke A, Wabbels B, et al. Impaired sleep quality and restless legs syndrome in idiopathic focal dystonia: a controlled study. J Neurol (2011) 258:1835-40. doi:10.1007/s00415-0116029-6

131. Kumru H, Santamaria J, Belcher R. Variability in the Epworth sleepiness scale score between the patient and the partner. Sleep Med (2004) 5:369-71. doi:10.1016/j.sleep.2004.03.003

Conflict of Interest Statement: The authors declare that the research was conducted in the absence of any commercial or financial relationships that could be construed as a potential conflict of interest.

Copyright (c) 2018 Kurtis, Balestrino, Rodriguez-Blazquez, Forjaz and MartinezMartin. This is an open-access article distributed under the terms of the Creative Commons Attribution License (CC BY). The use, distribution or reproduction in other forums is permitted, provided the original author(s) and the copyright owner are credited and that the original publication in this journal is cited, in accordance with accepted academic practice. No use, distribution or reproduction is permitted which does not comply with these terms. 